\title{
Candida albicans commensalism in the oral mucosa is favoured by limited virulence and metabolic adaptation.
}

Christina Lemberg ${ }^{1,2, \#, ~ K o n t x i ~ M a r t i n e z ~ d e ~ S a n ~ V i c e n t e, ~}$ Altmeier ${ }^{1,2}$, Van Du T. Tran 3 , Sara Amorim-Vaz ${ }^{4}$, Laxmi Shanker Rai ${ }^{5}$, Christophe d'Enfert ${ }^{5}$, Marco Pagni ${ }^{3}$, Dominique Sanglard ${ }^{4}$ and Salomé LeibundGut-Landmann ${ }^{1,2, *}$

${ }^{1}$ Section of Immunology, Vetsuisse Faculty, University of Zürich, Winterthurerstrasse 266a, CH-8057 Zürich, Switzerland.

2 Institute of Experimental Immunology, University of Zürich, Winterthurerstrasse 190, CH8057 Zürich, Switzerland

${ }^{3}$ Vital-IT Group, SIB Swiss Institute of Bioinformatics, Lausanne, Switzerland

${ }^{4}$ Institute of Microbiology, University of Lausanne and University Hospital Center, Lausanne, Switzerland

${ }^{5}$ Institut Pasteur, Université de Paris, INRAE, USC2019, Unité Biologie et Pathogénicité Fongiques, F-75015 Paris, France

\# Equal contribution

* Corresponding author: salome.leibundgut-landmann@uzh.ch

Keywords: Candida albicans, commensalism, oral mucosa, filamentation, metabolic adaptation 
bioRxiv preprint doi: https://doi.org/10.1101/2021.10.11.463879; this version posted October 11, 2021. The copyright holder for this

\section{ABSTRACT (MAX 300 WORDS)}

As part of the human microbiota, the fungus Candida albicans colonizes the oral cavity and other mucosal surfaces of the human body. Commensalism is tightly controlled by complex interactions of the fungus and the host to preclude fungal elimination but also fungal overgrowth and invasion, which can result in disease. As such, defects in antifungal T cell immunity render individuals susceptible to oral thrush due to interrupted immunosurveillance of the oral mucosa. The factors that promote commensalism and ensure persistence of $C$. albicans in a fully immunocompetent host remain less clear. Using an experimental model of C. albicans oral colonization in mice we explored fungal determinants of commensalism in the oral cavity. Transcript profiling of the oral isolate 101 in the murine tongue tissue revealed a characteristic metabolic profile tailored to the nutrient poor conditions in the stratum corneum of the epithelium where the fungus resides. Metabolic adaptation of isolate 101 was also reflected in enhanced nutrient acquisition when grown on oral mucosa substrates. Persistent colonization of the oral mucosa by C. albicans also correlated inversely with the capacity of the fungus to induce epithelial cell damage and to elicit an inflammatory response. Here we show that these immune evasive properties of isolate 101 are explained by a strong attenuation of a number of virulence genes, including those linked to filamentation. De-repression of the hyphal program by deletion or conditional repression of $N R G 1$ abolished the commensal behaviour of isolate 101, thereby establishing a central role of this factor in the commensal lifestyle of C. albicans in the oral niche of the host.

\section{AUTHOR SUMMARY (150-200 WORDS)}

The oral microbiota represents an important part of the human microbiota and includes several hundreds to several thousands of bacterial and fungal species. One of the most prominent fungus colonizing the oral cavity is the yeast Candida albicans. While the presence of $C$. albicans usually remains unnoticed, the fungus can under certain circumstances cause lesions on the lining of the mouth referred to as oral thrush or contribute to other common oral diseases such as caries. Maintaining $C$. albicans commensalism in the oral mucosa is therefore of utmost importance for oral health and overall wellbeing. While overt fungal growth and disease is limited by immunosurveillance mechanisms during homeostasis, C. albicans strives to survive and evades elimination from the host. Here, we show that while commensalism in the oral cavity is characterized by a restricted fungal virulence and hyphal program, enforcing filamentation in a commensal isolate is sufficient for driving pathogenicity and fungus-induced inflammation in the oral mucosa thwarting persistent colonization. Our results further support a critical role for specialized nutrient acquisition allowing the fungus to thrive in the nutrient poor environment of the squamous epithelium. Together, this work revealed key determinants of C. albicans commensalism in the oral niche. 
bioRxiv preprint doi: https://doi.org/10.1101/2021.10.11.463879; this version posted October $11,2021$. The copyright holder for this preprint (which was not certified by peer review) is the author/funder, who has granted bioRxiv a license to display the preprint in perpetuity. It is made available under aCC-BY 4.0 International license.

\section{INTRODUCTION}

Candida albicans is a prominent member of the human mycobiota in the oral, gastrointestinal and the vaginal mucosa. As a pathobiont, C. albicans can also cause infections reaching from mild superficial manifestations to rare but more severe and frequently life-threatening systemic candidiasis (Calderone and Clancey, 2012). Infections occur primarily in immunocompromised individuals, with mucocutaneous candidiasis developing most frequently in patients with acquired or inherited defects in T cell and IL-17 immunity (Li et al., 2017). While intact host defences are critical for preventing C. albicans overgrowth and tissue invasion, the balance between commensalism and disease also depends on the virulence state of the colonizing fungal isolate. Fungal pathogenicity can be modulated by the immune system (Ost et al., 2021), but importantly, C. albicans isolates also differ by intrinsic differences in virulence. The species of $C$. albicans displays a large genetic diversity, and although the genetic landscape of $C$. albicans has been described in some details (Ropars et al., 2018), functional consequences of these intraspecies variations at the host interface are less clear. Experimental infection studies in previously $C$. albicans-naïve mice with small sets of fungal isolates revealed diverse outcomes in terms of host survival (in the model of systemic candidiasis) or in terms of persistence of colonization (in the model of oropharyngeal candidiasis) (Hirakawa et al., 2015; MacCallum et al., 2009; Marakalala et al., 2013; Schönherr et al., 2017). The molecular basis for the commensal versus pathogenic lifestyle of phenotypically distinct natural isolates of $C$. albicans remains ill defined. Some pathogenicity traits of $C$. albicans have been identified in the gastrointestinal tract (Mishra and Koh, 2021). The generation of isogenic mutants of the highly virulent reference isolate SC5314 and within-host evolution experiments with SC5314 allowed the identification of genetic determinants that govern the ability of $C$. albicans to inhabit the gastrointestinal tract (Noble et al., 2010; Pande et al., 2013; Perez et al., 2013; Tso et al., 2018; Znaidi et al., 2018). While non-filamentous morphologies are generally good colonizers, hyphae are less fit in this compartment but instead may be better suited for epithelial translocation and invasive infections (Bohm et al., 2017; Pande et al., 2013; Witchley et al., 2019). Beyond morphology, fungal adhesion and host cell damage induction can also modulate gut colonization (Allert et al., 2018). Much less is known about the fungal determinants that enable colonization of the oral mucosa, an important niche of the fungus (Ghannoum et al., 2010) and a frequent site of C. albicans-mediated disease manifestation (Scully et al., 1994). The oral cavity differs significantly from the gastrointestinal tract and other commensal niches of $C$. albicans with respect to physico-chemical properties such as $\mathrm{pH}$ and $\mathrm{O}_{2}$ content, the nature of the lining epithelium and the composition of the microbiota (Gaffen and Moutsopoulos, 2020). Moreover, because the oral cavity is not covered with mucus and is not contained such as the intestine where $C$. albicans mainly lingers in the tubular lumen, the fungus in the oral cavity resides within the stratified epithelium and as such is in constant physical contact with oral keratinocytes and interepithelial immune cells.

During oropharyngeal candidiasis (OPC) in mice, which are not naturally colonized with $C$. albicans, virulent isolates of $C$. albicans trigger a strong inflammatory host response that results in rapid clearance of the fungus from the oral mucosa. In contrast, low virulent isolates elicit only a limited host response which coincides with fungal persistence in the stratum corneum (Schönherr et al., 2017). In the latter case, commensal colonization of fully immunocompetent and non-antibiotically treated wild type mice can last for over a year (Kirchner et al., 2019). While the differential response of the host to commensal versus pathogenic isolates of $C$. albicans was dissected in some detail, the fungal factors that determine the commensal lifestyle of $C$. albicans in the oral niche remain to be explored. Using the prototypical commensal isolate 101 characterized by long persistence in the OPC 
mouse model, the objective of this study was to determine how the fungus survives and evades the host in this specific tissue compartment. Transcript profiling of the isolate inside the host tissue revealed hallmarks of commensalism in the oral niche. Expression levels of the transcription factor $N R G 1$ was a determining factor in the commensalism of isolate 101, the relevance of which we confirmed by complementary genetic approaches. 
bioRxiv preprint doi: https://doi.org/10.1101/2021.10.11.463879; this version posted October 11,2021 . The copyright holder for this preprint (which was not certified by peer review) is the author/funder, who has granted bioRxiv a license to display the preprint in perpetuity. It is made available under aCC-BY 4.0 International license.

\section{RESULTS}

\section{C. albicans isolate 101 displays reduced filamentation compared to SC5314}

The commensal $C$. albicans isolate 101 efficiently and persistently colonizes the oral epithelium of wild type C57BL/6 mice when administered sublingually. Fungal elements locate to the stratum corneum where they persist without penetrating deeper epithelial layers of the stratified epithelium (Schönherr et al., 2017). This is in contrast to the highly virulent isolate SC5314, which causes damage in the oral epithelium and invades the stratified epithelium to deeper layers. To determine the characteristics of fungal commensalism in the oral niche, we first assessed the morphology of isolate 101 on PAS-stained tissue sections and after isolation of the fungus from the tongue by $\mathrm{KOH}$ (Figure 1A, B). The fungus was predominantly in the hyphal form, whereby hyphae appeared to be slightly shorter in comparison to those of the isolate SC5314. By histology we also observed some pseudohyphae.

Because quantification of filament length is hardly possible in vivo on tissue sections, we examined filamentation in vitro in serum containing medium. Filaments of isolate 101 were consistently shorter than those of SC5314, in both presence or absence of oral keratinocytes (Figure 1C-H). The morphogenetic defect of isolate 101 was most pronounced when cultured on Spider agar (Figure 1I). The commensal phenotype of isolate 101 was thus associated an impairment in filamentation, although the isolate was able to form hyphae, especially at the interface with the host.

\section{Isolate 101 is less invasive than SC5314}

In line with the impaired filamentation phenotype, isolate 101 was also less invasive in YNB agar containing BSA when compared to SC5314 (Figure 2A). Similarly, when probing invasion of TR146 oral keratinocytes, a reduced proportion of 101 hyphae invaded host cells (Figure 2B).

Assaying fungal invasion of cultured keratinocyte monolayers monitors the invasion of $C$. albicans filaments into individual cells, while colonization of the stratified epithelium of the oral mucosa comprises both intra- and intercellular invasion processes. Probing the invasive capacities of isolate 101 in a fully differentiated three-dimensional skin model reproduced the situation in the oral epithelium in vivo, whereby isolate 101 remained mostly restricted to the outermost keratinized layer, while SC5314 penetrated deep into the tissue, reaching even the supporting fibroblasts that underlie the epithelium in this model (Figure 2C). This finding indicated that the localization of $C$. albicans inside the stratified epithelium is an intrinsic property of the isolate in interaction with epithelial cells. This localization was independent of immune cells that represent an integral component of the mucosal tissue in vivo. The less invasive phenotype of isolate 101 in reconstituted human epidermis coincided with its low epithelial cell damage capacity (Figure 2D) and production of inflammatory cytokines (Figure 2E, F), similarly to the situation in keratinocyte monolayer cultures (Figure 2G, H).

\section{Altered interaction of isolate 101 with keratinocytes does not curb the initial infection process in the oral epithelium.}

To assess whether the observed phenotypic differences between isolates 101 and SC5314 affected their initial colonization of the host tissue, we tested their interaction with the oral epithelium in a competitive infection setting. To distinguish the two isolates after coinfection, we used a mCherry-expressing version of isolate 101 (Kirchner and LeibundGutLandmann, 2020) and a GFP-expressing version of SC5314 (Barelle et al., 2004), mixed in equal amounts (Figure S1A). After 1 day, both isolates were recovered from the infected tongue at a 1:1 ratio, comparable to the ratio in the infection inoculum, indicating that both 
isolates seeded the oral epithelium with comparable efficiency (Figure 3A), confirming previous findings from single-strain infections (Schönherr et al., 2017). The initial steps of the infection process seem thus not to be affected by differences in the isolates' capacity to filament or to interact with keratinocytes in vitro (invasion and damage induction). In single infections, the cellular damage caused by high-virulent isolates such as SC5314 triggers an acute inflammatory response in the infected epithelium characterized by rapid production and release of pro-inflammatory cytokines by epithelial cells, including IL-1 $\alpha$ and chemokines, which trigger the recruitment of neutrophils and inflammatory monocytes from the circulation to the site of infection (Altmeier et al., 2016; Moyes et al., 2016). A consequence of the acute host response in the oral mucosa is the rapid elimination of the fungus from the experimentally infected host. In contrast, low-damaging isolates which trigger a limited or no inflammatory response upon colonization/infection persist in the epithelium over time (Kirchner et al., 2019; Schönherr et al., 2017).

Therefore, the question arose whether in a co-infection setting, where isolate 101 is exposed to an inflammatory environment induced by SC5314, it would be cleared from the oral mucosa, similarly to SC5314 itself. We confirmed that the overall inflammatory response was indeed comparable in the co-infection setting as in a single infection with SC5314 (Figure

3B, Figure S1B). We then assessed the fungal burden in the tongue by day 7 post-infection, when SC5314 is cleared in a single infection setting (Conti et al., 2009; Gladiator et al., 2013). Tongue fungal counts in co-infected animals remained high and were comparable as in isolate 101 single-infected mice (Figure 3C). Enumeration of the colonies based on their fluorescent label revealed that all were expressing mCherry and hence identified as 101, while no SC5314 colonies were recovered (Figure 3C). Together, this indicates that, even in a co-infection setting, isolate 101 persists in the oral mucosa and resists the inflammatory environment.

\section{Persistence of isolate 101 in the oral mucosa is associated with a reduced virulence profile}

To obtain a more comprehensive and unbiased picture of the properties of isolate 101, we acquired the transcriptomes of isolates 101 and SC5314 as a reference within the oral mucosa at three consecutive time points (day 1, day 3, day 7 post-infection). However, due to its rapid clearance from the oral mucosa the analysis of isolate SC5314 transcriptome was limited to day 1 post-infection. We also included samples from in vitro-induced hyphae of both isolates, whereby we spiked this RNA into RNA isolated from naïve tongues. Fungal RNA was enriched using a hybridization technology aimed at enriching fungal RNAs within infected host tissues where they usually account for only a small fraction of the overall RNA (Amorim-Vaz et al., 2015b).

Principal component analysis showed distinct transcript profiles of isolates 101 and SC5314, both under in vitro or in vivo conditions (Figure 4A). Moreover, the transcriptome of isolate 101 changed over time and became increasingly distinct from the one of SC5314 on day 1 post-infection (Figure 4A).

Qualitative differences of the transcriptional response of isolate 101 compared to SC5314 were reflected in a diminished expression of genes associated with filamentous growth, virulence and immune activation, with differences increasing over time (Figure 4B, Figure S2). Among the most strongly downregulated genes in isolate 101 featured genes encoding adhesins and invasins, namely $A L S 1$ and $A L S 3$ (Phan et al., 2007; Sheppard et al., 2004), aspartyl proteases, namely SAP4, SAP6 and SAP8 linked to deep tissue invasion (Schaller et al., 2000), and the damage-inducing factor, namely ECE1 (Moyes et al., 2016) (Figure 4D). In contrast, the increased expression of $S A P 1$ and $S A P 3$ by isolate 101 in the oral mucosa was consistent with the preferential residence of this isolate in the upper layers of the stratified 
epithelium (Schaller et al., 2000). Genes encoding transcription factors associated with filamentous growth including $C P H 1, H G C 1, B R G 1$ and UME6 were also downregulated in isolate 101 as compared to SC5314. Interestingly, $N R G 1$ that encodes a repressor of the filamentation program (Murad et al., 2001) was strongly upregulated (Figure 4D). The difference in morphogenesis between the two isolates was further associated by differential regulation of cell wall and biofilm associated genes (Figure 4D).

Differential expression of virulence and morphogenesis genes between isolates 101 and SC5314 in the murine oral mucosa was largely conserved under in vitro culture conditions with serum (Figure 4D). RT-qPCR assays with RNA isolated from $C$. albicans after exposure to TR146 keratinocytes further confirmed the RNAseq data (Figure S3A-B). Overall, the transcriptomic data are well in agreement with the phenotypic data indicating that isolate 101 is less filamenting, less invasive, less tissue damaging and less immune activating than SC5314 (Figures 1 and 2) (Kirchner et al., 2019; Schönherr et al., 2017). Of note, the changes in virulence gene expression increased over time and largely accounted for the time-dependent shifts in the transcript profile of isolate 101 (Figure 4A).

Among the genes displaying an increased expression in isolate 101 relative to SC5314 were stress-response genes, especially those implicated in ROS detoxification and the response to oxidative stress (Figure 4D). This observation is in support of the persistent phenotype of the strain in the mucosal tissue, even under inflammatory conditions as during co-infection with an inflammation-inducing isolate (Figure 3).

\section{Isolate 101 is metabolically adapted to the oral niche}

In addition to the filamentation-related gene expression differences described above, we identified a prominent metabolic signature in isolate 101. A large group of genes associated with metabolic processes, including amino acid and phospholipid catabolism, and with glycolysis and pyruvate metabolism were overexpressed in isolate 101 in comparison to SC5314 (Figure 4C-D). These differences were apparent at every time points both under in vivo and in vitro conditions (Figure 4C-D, Figure S3C). Moreover, genes encoding membrane transporters, including oligopeptide transporters and glucose, dicarboxylate and monocarboxylate transporters were upregulated in the murine tissue on at least one time point analysed (Figure 4C). Taken together, these data suggested that isolate 101 is metabolically adapted and employs an efficient strategy for nutrient acquisition in the oral epithelium of the host where nutrients are limited.

In support of this notion, isolate 101 featured enhanced phospholipase activity in comparison to SC5314 when examined experimentally on original Prices' egg yolk agar (Figure S3D). Moreover, we observed that isolate 101 displayed an enhanced growth under conditions mimicking those in the oral mucosa, including the replacement of glucose as the carbon source by N-acetlyglucosamine (GlcNAc), an amide derivative sugar abundant in the saliva and in the cell wall and biofilm extracellular matrix of oral bacteria (Battistone and Burnett, 1961; Moye et al., 2014). The enhanced growth phenotype was also visible on casamino acids, a mixture of free amino acids and small peptides that mimics the protein-rich environment of the stratum corneum of the tongue (Kalinin et al., 2002) (Figure S3D). The better adaptation of isolate 101 compared to SC5314 in sensing and using GlcNAc was further evidenced by its resistance to GlcNAc-induced cell death (Figure S3E). GlcNAc serves as a signal of nutrient availability in C. albicans, inducing entry into mitotic cell cycle and rapid cell growth. However, incubation in the presence of GlcNAc without other nutrients to support growth results in cell death due to the accumulation of intracellular ROS (Du et al., 2015). While we confirmed this phenomenon with strain SC5314 (Figure S3F), for which it was originally demonstrated (Du et al., 2015), isolate 101 survived unabatedly under these conditions (Figure S3F), in line with its increased expression of oxidative stress 
bioRxiv preprint doi: https://doi.org/10.1101/2021.10.11.463879; this version posted October $11,2021$. The copyright holder for this preprint (which was not certified by peer review) is the author/funder, who has granted bioRxiv a license to display the preprint in perpetuity. It is made available under aCC-BY 4.0 International license.

resistance genes (Figure 4D). Altogether, these findings indicated that persistent growth of isolate 101 in the oral cavity could be favoured not only by restricted filamentation and virulence, but also by metabolic adaption to the nutrient-poor environment in the stratified epithelium.

\section{Overexpression of NRG1 in SC5314 restrains its virulence potential in vitro and in vivo}

Given the pronounced differences between isolates 101 and SC5314, we speculated that modulating the expression of virulence traits in isolate 101 would alter its phenotype and change its behaviour at the interface with the host. Given the link between damage induction and induction of inflammation in the host by highly virulent strains of $C$. albicans and because $E C E 1$ plays a prominent role in this process, we attempted to heterologously express $E C E 1$ of strain SC5314 in isolate 101. Despite choosing the strong TDH3 promoter, we could not achieve $E C E 1$ expression levels that were high enough to increase damage induction in keratinocytes (Figure S4A). The failure of achieving enhanced virulence in the commensal isolate 101 might be due to inadequate posttranslational processing of Ecelp required for generation of the peptide toxin known as Candidalysin (Richardson et al., 2018) and the need for delivery of the toxin to the host cells via an invasion pocket at the hyphal tip (Mogavero et al., 2021). The reduced filamentation of isolate 101 may not suffice those criteria. We therefore turned our focus onto transcription factors that regulate $C$. albicans virulence more broadly and that were differentially regulated between the highly virulent SC5314 isolate and the low-virulent isolate 101. Among the most strongly regulated genes in isolate 101 was $N R G 1$ that encodes a repressor of the filamentation program. Given the filamentation phenotype of isolate 101 and the central role of filamentation C. albicans pathogenicity, we speculated that manipulating the expression of $N R G 1$ in isolate 101 might alter its phenotype and make it more virulent. Vice versa, overexpressing NRG1 in SC5314 might have the opposite effect. Therefore, we made use of a SC5314-based isolate that conditionally overexpresses NRG1 upon doxycycline (Dox) treatment (Znaidi et al., 2018). Overexpression of $N R G 1$ (Figure 5A) did not affect the growth rate of the isolate (Figure S4B), but resulted in a defect in filamentation, both on YPD agar and in liquid medium. Dox-treated SN76 ${ }^{N R G I-}$ ${ }^{\mathrm{OE}}$ cells, but not cells of a Dox-treated control isolate, displayed a yeast/pseudophyphal morphology (Figure 5B-C). Moreover, $N R G 1$ overexpression was accompanied by reduced expression of diverse virulence genes such as ECE1, ALS3 and HWP1 (Figure 5D) and a reduced capacity to induce damage in TR146 keratinocytes (Figure 5E).

Based on these data, we wondered whether modulation of NRG1 levels would also affect the behaviour of $C$. albicans cells in vivo in the oral mucosa. Pre-treatment of the isolate and supplementation of the drinking water of the mice with doxycycline had no effect on initial steps of the infection process (Figure 5F). However, the acute inflammatory response characterized by neutrophil recruitment to the site of infection in consequence of epithelial damage, was much reduced in mice infected with $C$. albicans strain overexpressing NRG1 in comparison to controls as evidenced on histology sections (Figure 5G) and by enumeration of neutrophils in infected tongues by flow cytometry (Figure 5H). The reduced inflammatory response of the host was accompanied by a delay in fungal clearance which manifested by elevated fungal loads on day 3 post-infection in case of the $N R G 1$-overexpressing C. albicans strain in comparison to all controls (Figure 5I). By day 7 however, mice had fully cleared the fungus and regained their initial weight (Figure 5J).

We also examined the consequences of modulating expression of another gene, CRZ2, which was also differentially expressed between isolates SC5314 and 101 and whose overexpression in SC5314 results in enhanced fitness during gastrointestinal colonization (Znaidi et al., 2018). While overexpression of CRZ2 in SC5314 induced a slight change in colony morphology and a reduction in epithelial damage induction in vitro (Figure S4C-E), 
bioRxiv preprint doi: https://doi.org/10.1101/2021.10.11.463879; this version posted October $11,2021$. The copyright holder for this preprint (which was not certified by peer review) is the author/funder, who has granted bioRxiv a license to display the preprint in perpetuity. It is made available under aCC-BY 4.0 International license.

we did not observe an effect of $C R Z 2$ overexpression on the inflammatory host response or a prolongation of oral colonization in vivo (Figure S4F-I).

\section{Reduced expression of NRG1 in isolate 101 increases its pathogenicity}

Following from the results obtained with an C. albicans SC5314 derivative overexpressing $N R G 1$, which revealed impaired virulence in vitro and in vivo in the OPC model, we wondered whether the opposite could be achieved in isolate 101, namely whether reducing $N R G 1$ expression levels in this isolate would be able and sufficient to increase its pathogenicity. Deletion of one or both alleles of $N R G 1$ in isolate $101\left(101^{\text {nrgl } 14 \mathrm{NRG} 1}\right.$ and $101^{\text {nrg } 14 / 4}$, Figure 6A) entailed a dose-dependent increase in expression of determining virulence factors, including $A L S 3, E C E 1$ and $H W P 1$ (Figure 6B). Expression of $A L S 3$ in $101^{\text {nrgl } 1 / 4}$ reached levels even higher than those in wild type SC5314 (Figure 6B). The altered gene expression profile correlated with increased filamentation. Both, the heterozygous and the homozygous deletion mutants formed longer filaments than the parental isolate 101 when exposed to human keratinocytes (Figure 6C, Figure S5A). Increased filamentation of the mutants was also observed on Spider agar and on YPD agar containing different carbon sources (Figure S5B-C) and this correlated with enhanced invasion properties (Figure S5C). Acquisition of these important virulence traits was however not sufficient for induction of detectable cellular damage in TR146 keratinocytes (Figure 6D). Importantly, deletion of NRG1 in isolate 101 resulted in enhanced virulence in the oral mucosa of experimentally infected mice in vivo. Deletion of a single copy of the gene was sufficient to elicit an enhanced inflammatory response characterized by increased expression of inflammatory cytokines and mediators and enhanced infiltration of neutrophils and monocytes into the colonized tongue as assessed by flow cytometry and on histology sections on day 1 post-infection, while colonization loads were comparable between $101^{\text {rrg } 1 \Delta \text { NRG1 }}$ and the parental isolate at this time point (Figure 6E-H). Notably, the enhanced inflammatory response triggered by $101^{\text {nrgl } 1 \triangle N R G 1}$ in the host impaired fungal colonization and resulted in a reduced fungal load on day 7 post-infection.

Unfortunately, we were unable to extend our analysis to the homozygous deletion mutant. Isolate $101^{\text {nrg } 1 \Delta / \Delta}$ tended to form clumps in culture, which reduced the efficiency of the isolate to colonize the murine oral mucosa (Figure 6E). Clumping could not be prevented by filtering the isolate before applying it to the animals. The inequality in fungal load recovered from the tongue on day 1 post-infection (Figure S5D) prevented any further analyses of the $101^{\text {nrgl } 1 / 4}$ mutant in vivo.

We therefore pursued a second independent approach to suppress $N R G 1$ expression in isolate 101 very efficiently using a Dox-dependent TET-off system. Notably, one $N R G 1$ allele was under the control of the TET promoter in the designed isolate, while the other was deleted (101 ${ }^{\text {rrg } 14 / \mathrm{pTET}-\mathrm{NRG1})}$ (Figure S6A-B). As little as $1 \mu \mathrm{g} / \mathrm{ml}$ of Dox resulted in a strong reduction of $N R G 1$ expression in isolate $101^{\mathrm{nrg} 14 / \mathrm{pTET}-\mathrm{NRG} 1}$ without overt clumping of the isolate (Figure 7A, Figure S6C). Similar as with the $N R G 1$ deletion mutants, the reduction of $N R G 1$ transcript levels was accompanied by a dose-dependent increase in the expression of various virulence factors (Figure 7B, Figure S6C). Dox -induced suppression of $N R G 1$ expression also resulted in enhanced filamentation, both under YPD culture conditions at $37^{\circ} \mathrm{C}$ without addition of FCS or any other known hyphae-inducing agents (Figure 7C), and after exposure to TR146 keratinocytes (Figure 7D, Figure S6D). Importantly, these phenotypic and functional changes were accompanied by enhanced pathogenicity in vivo as indicated by the

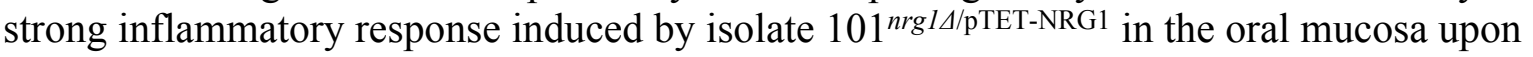
Dox treatment (Figure 7F-G). Together, these results demonstrated that NRG1 acts as a central regulator of $C$. albicans pathogenicity in the oral cavity and that suppression of high 
bioRxiv preprint doi: https://doi.org/10.1101/2021.10.11.463879; this version posted October $11,2021$. The copyright holder for this preprint (which was not certified by peer review) is the author/funder, who has granted bioRxiv a license to display the preprint in perpetuity. It is made available under aCC-BY 4.0 International license.

$N R G 1$ expression levels in the commensal stain 101 is sufficient to increase its virulence and to alter the fungus-host interplay at the epithelial barrier.

\section{DISCUSSION}

The oral cavity is an important niche for $C$. albicans colonization (Ghannoum et al., 2010). It also represents a site where infections caused by $C$. albicans frequently manifest (Scully et al., 1994). Our understanding of the fungal cues that allow C. albicans to persist in this niche and to be tolerated by the host without causing disease, remains incomplete. To fill this gap in knowledge, we employed a model of oral colonization in mice and examine requirements for C. albicans commensalism.

\section{NRG1 as genetic driver of commensalism in the oral mucosa}

Transcript profiling of $C$. albicans isolate 101 in the oral tissue and functional studies with the isolate in host-involving and host-free conditions revealed a pronounced reduction in multiple virulence traits, including filamentation, invasion and damage induction. Based on this information, we attempted to increase virulence of isolate 101. Overexpression of specific virulence genes, such as $E C E 1$, was not sufficient to induce a gain in pathogenicity in isolate 101, possibly consistent with the recent demonstration that the full damage potential of $C$. albicans depends not only on strong Ecel expression but also coordinated delivery of fully processed and secreted Candidalysin in invasion pocket created by invasive hyphae (Mogavero et al., 2021). Of note, we expressed the entire ECE1 gene originating from SC5314 under the strong TDH3 promoter, including the sequences flanking peptide 3 for optimal Candidalysin processing, to exclude suboptimal processing of Ecelp as recently reported (Liu et al., 2021).

Strengthening the hyphal program in isolate 101 by suppressing $N R G 1$ expression resulted in major changes in its behaviour in the oral cavity. Forced induction of filamentation in the normally avirulent isolate 101 was sufficient to elicit an inflammatory response in the colonized host and to impair colonization, indicating that reduced filamentation is a major determinant of commensalism in the oral cavity. This is reminiscent of what was described for other commensal niches of C. albicans (Peters et al., 2014; Witchley et al., 2019). Despite the parallels in the role of filamentation in commensalism in various mucosal epithelia, there are also important differences between different sites. As such, SC5314CRZ2-OE acquires enhanced fitness during gut colonization (Znaidi et al., 2018) but not during OPC suggesting that commensalism in the gastrointestinal tract and in the oral cavity integrates different fungal effectors. Morphotype switching drives $C$. albicans pathogenicity also during systemic infection (Saville et al., 2003). Of interest, rapid yeast proliferation in internal organs can compensate for the lack of filamentation, as it was shown recently with an EEDI deficient mutant (Dunker et al., 2021).

$N R G 1$ is a transcriptional repressor of hyphae-specific genes and of genes required for the morphogenic switch (Braun et al., 2001). NRG1 transcription is downregulated under conditions promoting filamentation. Constitutive expression of NRG1 in SC5314 established the need of morphotype switching for pathogenicity of $C$. albicans during disseminated candidiasis (Saville et al., 2003), while enforced filamentation due to constitutive deletion of $N R G 1$ lowered intestinal colonization of C. albicans (Vautier et al., 2015). A limited degree of filamentation is however beneficial for commensalism in the gut: it has recently been shown to drive an IgA response targeting fungal hyphae, which in turn improves competitive 
bioRxiv preprint doi: https://doi.org/10.1101/2021.10.11.463879; this version posted October 11,2021 . The copyright holder for this preprint (which was not certified by peer review) is the author/funder, who has granted bioRxiv a license to display the preprint in perpetuity. It is made available under aCC-BY 4.0 International license.

fitness of C. albicans and promotes homeostasis (Ost et al., 2021). The role of $N R G 1$ as a driver of commensalism extends beyond the species of $C$. albicans: reduced virulence of $C$. dubliniensis was linked to the inability of this species to modulate NRG1 expression in response to environmental signals that promote filamentation in prototypic isolates of $C$. albicans (Moran et al., 2007).

The genetic basis for the commensal phenotype of $C$. albicans isolate 101 represents a significant challenge and remains to be established in the future, for instance to understand the differential expression of $N R G 1$ and other genes linked to filamentation and virulence in isolate 101 compared to SC5314. The species of $C$. albicans displays an intrinsically high diversity in its population genetic structure (Ropars et al., 2018). Individual isolates differ by a large number of nucleotides, and even after excluding synonymous and conserved polymorphisms between the two isolates the sequence differences remain numerous, not to mention higher order genomic differences (Abbey et al., 2011; Berman, 2016). The situation is further complicated by circuit diversification in regulatory networks that exist between isolates (Huang et al., 2019). This large complexity prevented us from yet identifying any specific genetic determinants underlying the commensal phenotype of isolate 101.

A genetic determinant of $C$. albicans commensalism in the vaginal mucosa was recently identified in the coding sequence of $E C E 1$, which affects processing of the damage causing peptide toxin and may thereby contribute to differential pathogenicity among clinical isolates (Liu et al., 2021). While this may explain, at least in part, the low virulence of isolate 529L in the OPC model (Rahman et al., 2007; Schönherr et al., 2017), it does not so for isolate 101, which displays the SC5314 isoform at the relevant ECE1 P2-P3 junction.

\section{Metabolic adaptation of C. albicans isolate 101}

Phenotypic differences between isolates 101 and SC5314 are multifactorial and go far beyond differences in filamentation, invasion and damage induction. The transcriptome of $C$. albicans isolate 101 in the oral tissue revealed a metabolic signature adapted for nutrient acquisition in this specific niche. In experimentally infected mice, commensal isolates are confined to the stratum corneum of the tongue (Schönherr et al., 2017), the outermost layer of the stratified epithelium composed of metabolically inactive corneocytes that form a tight and water impermeable barrier limiting nutrient availability (Candi et al., 2005). The absence of tissue damage by commensal isolates further limits access to nutrients inside host cells. The high expression of genes encoding proteases, oligopeptide transporters and amino acid catabolic enzymes indicates customized nutrient acquisition mechanisms being active in this protein-rich tissue compartment. Among the amino acid catabolic enzymes whose genes are especially highly expressed in isolate 101 were those involved in catabolism of Glycine and Glutamine, which are highly enriched in structural proteins of the cornified envelope of epithelium (Kalinin et al., 2002).

The selective localization to the stratum corneum may thus not simply be the consequence of impaired damage induction by isolate 101 but also reflect metabolic specialization to this niche. This is further supported by the expression of specific subsets of SAP genes with SAPI and $S A P 2$, which mediate initial invasion of the epithelium (Schaller et al., 2000), being highly expressed by isolate 101 in contrast to SAP6 and SAP8, which are associated with penetration of $C$. albicans to deeper epithelial layers (Schaller et al., 2000). The restricted localization of commensal C. albicans in the stratum corneum may promote fungal persistence in several ways: Exclusion from deeper layers of the epithelium limits induction and release of inflammatory mediators from metabolically active epithelial cells located in the stratum spinosum. It also protects the fungus from exposure to antifungal mechanisms of the epithelium such as antimicrobial peptides, which are lower in concentration towards the 
bioRxiv preprint doi: https://doi. org/10.1101/2021 10.11.463879; this version posted October 11, 2021. The copyright holder for this preprint (which was not certified by peer review) is the author/funder, who has granted bioRxiv a license to display the preprint in perpetuity. It is made available under aCC-BY 4.0 International license.

outside of the epithelium because the cornified envelope, a water-proof amalgam of crosslinked proteins and hydrophobic lipids, hardly provides access to water-soluble positively charged antimicrobial peptides. Enhanced resistance to host defences represents an additional mechanism of immune evasion that allows the fungus to survive homeostatic immunity, which the host raises to counteract fungal (over) growth (Kirchner and LeibundGut-Landmann, 2020). C. albicans isolate 101 did even resist the strong inflammatory host response to which it was exposed during co-infection with the highvirulent SC5314, which suggests the acquisition of several factors inducing host resistance by isolate 101. Among these, resistance to oxidative stress prevailing in 101 provides an advantage during exposure to extracellular ROS, e.g. from neutrophils. An enhanced oxidative stress response also contributes to protection from GlcNAc-induced cell death by counteracting the accumulation of intracellular ROS (Du et al., 2015). Resistance to oxidative stress may be further enhanced by GlcNAc and amino acids (Williams and Lorenz, 2020), which are favourably metabolized by isolate 101 . The metabolic profile of isolate 101 , which provides it with an advantage for thriving in the nutrient-poor cornified layer of the tongue epithelium, may favour the low pathogenicity of this isolate, however the mechanistic details of this association remain to be further addressed.

\section{Conclusions}

Together, our work sheds new light on fungal attributes of $C$. albicans commensalism in the oral cavity. Improved understanding of how the fungus prevents pathogenicity in various host niches paves the way for novel therapeutic approaches that aim not at eradicating the fungus but rather counteracting its virulence. This strategy has been successfully approached with antagonizing bacteria (Graf et al., 2019; Mailander-Sanchez et al., 2017) and compounds targeting $C$. albicans hyphae and biofilm formation via TUP1 have been developed (Hamdy et al., 2020). Based on this concept new opportunities may also open up for the NDV-3A vaccine, which can shift the hyphae/yeast balance by inducing ALS3-specific IgA (Ost et al., 2021). Targeting fungal virulence instead of the fungus' ability to thrive on colonized surfaces will further help limiting the rise in antifungal resistance. 
bioRxiv preprint doi: https://doi.org/10.1101/2021.10.11.463879; this version posted October 11 , 2021. The copyright holder for this preprint (which was not certified by peer review) is the author/funder, who has granted bioRxiv a license to display the preprint in perpetuity. It is made available under aCC-BY 4.0 International license.

\section{METHODS}

\section{Fungal strains}

Strains used in this study are listed in Table S1. All strains were maintained on YPD agar for short term and in glycerol-supplemented medium at $-80^{\circ} \mathrm{C}$ for long term storage. Cultures were inoculated at $\mathrm{OD}_{600}=0.1$ in YPD medium (using a pre-culture to adjust the $\mathrm{OD}_{600}$ ) and grown at $30^{\circ} \mathrm{C}$ and $180 \mathrm{rpm}$ for $15-18$ hours. For Dox inducible strains, the cultures were supplemented with $50 \mu \mathrm{g} / \mathrm{ml}$ (in case of SC5314 ${ }^{\mathrm{NRG1}-\mathrm{OE}}$ ) or $10 \mu \mathrm{g} / \mathrm{ml}$ Dox (in case of 101 nrg14/pTET-NRG1, unless stated otherwise). At the end of the culture period, yeast cells were washed in PBS and their concentration was determined by spectrophotometry, whereby 1 $\mathrm{OD}_{600}=10^{7}$ yeast cells.

Table S1. C. albicans strains used in this study

\begin{tabular}{|c|c|c|c|c|}
\hline Strain & Collection \# & genotype & Parental & reference \\
\hline SC5314 & CA1 & Clinical isolate & & $\begin{array}{l}\text { (Gillum et } \\
\text { al., 1984) }\end{array}$ \\
\hline SC5314 GFP & CA2 & pACT1-GFP & CAI4 & $\begin{array}{l}\text { (Barelle et } \\
\text { al., 2004) }\end{array}$ \\
\hline 101 & CA117 & Clinical isolate & & $\begin{array}{l}\text { (Schönherr } \\
\text { et al., 2017) }\end{array}$ \\
\hline $101^{\text {mCherry }}$ & $\begin{array}{l}\text { DSY4718 / } \\
\text { CA124 }\end{array}$ & $A D H 1:: \mathrm{pADH}-\mathrm{Cherry}-S A T 1$ & 101 & $\begin{array}{l}\text { (Kirchner } \\
\text { and } \\
\text { LeibundGut- } \\
\text { Landmann, } \\
\text { 2020) }\end{array}$ \\
\hline SN76 & $\begin{array}{l}\text { CEC4665 / } \\
\text { CA210 }\end{array}$ & $\begin{array}{l}\mathrm{SN} 76 \text { ADH1/adh1 } \because: \mathrm{P}_{T D H 3}-\text { carTA }:: S A T 1 \\
\arg 4 \Delta:: \text { CaARG4 his } 1 \Delta:: \text { hisG/HIS1 } \\
\text { RPS1/RPS1 }: \text { CIp10 }\end{array}$ & CEC4642 & this study \\
\hline SN76 ${ }^{\text {NRG1-OE }}$ & $\begin{array}{l}\text { CEC6039/ } \\
\text { CA227 }\end{array}$ & 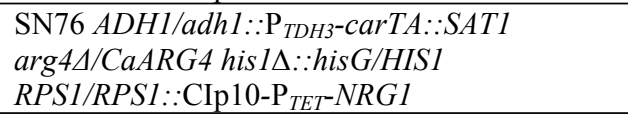 & CEC4642 & this study \\
\hline SC5314CTRL2 & $\begin{array}{l}\text { CEC4442 / } \\
\text { CA222 }\end{array}$ & 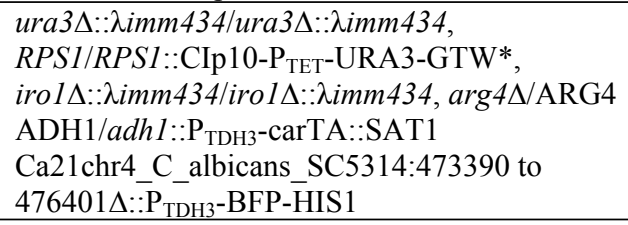 & CEC3783 & $\begin{array}{l}\text { (Znaidi et } \\
\text { al., 2018) }\end{array}$ \\
\hline SC5314 ${ }^{C R Z 2-O E}$ & $\begin{array}{l}\text { CEC4439/ } \\
\text { CA221 }\end{array}$ & 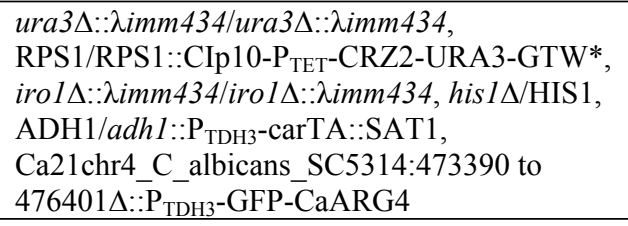 & CEC3781 & $\begin{array}{l}\text { (Znaidi et } \\
\text { al., 2018) }\end{array}$ \\
\hline & DSY5577 & $n r g 1 \Delta:: F R T-S A T 1-F R T / N R G 1$ & DSY4709 & this study \\
\hline $101^{\text {nrgl IANRG1 }}$ & $\begin{array}{l}\text { DSY5592/ } \\
\text { CA245 }\end{array}$ & $n r g 1 \Delta:: F R T / N R G 1$ & DSY5577 & this study \\
\hline $101^{\text {nrgld/4 }}$ & $\begin{array}{l}\text { DSY5599/ } \\
\text { CA246 } \\
\end{array}$ & $n r g 1 \Delta:: F R T / n r g 1 \Delta:: F R T-S A T 1-F R T$ & DSY5592 & this study \\
\hline & DSY5617 & $n r g 1 \Delta:: F R T / n r g 1 \Delta:: F R T$ & DSY5592 & this study \\
\hline $\begin{array}{l}101^{\text {nrgl } 1 / \mathrm{pTET}-} \\
\text { NRGI }\end{array}$ & $\begin{array}{l}\text { DSY5625/ } \\
\text { CA252 }\end{array}$ & $\begin{array}{l}n r g 1 \Delta:: F R T / \text { pTET-O7-NRG1::NAT1 } \\
A D H 1:: \text { pDS2142 }\end{array}$ & DSY5617 & this study \\
\hline DSY5622 & DSY5622 & $\begin{array}{l}\text { ura } 3 \Delta:: \lambda \text { imm 434/ura3 } \Delta:: \lambda \text { imm } 434, \\
\text { iro } 1 \Delta:: \lambda \text { imm } 434 / \text { iro } 1 \Delta:: \lambda \text { imm } 434, \text { arg } 4 \Delta / A R G 4 \text {, } \\
\text { his } 1 \Delta:: \text { his G/HIS1, RPS1/RPS1::CIp-PTET-SP- } \\
\text { gLUC59 }\end{array}$ & CEC161 & this study \\
\hline DSY5624 & DSY5624 & 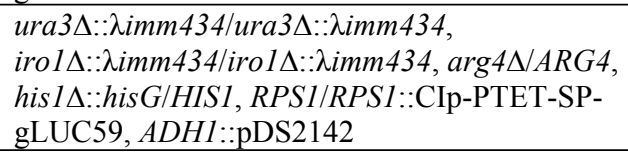 & DSY5622 & this study \\
\hline $101^{T D H 3-E C E 1}$ & DSY5209 & TDH3::pDS2037 & 101 & this study \\
\hline
\end{tabular}




\section{Generation of NRG1 overexpressing mutants}

$N R G 1$ was PCR amplified from C. albicans SC5314 genomic DNA using primers 23_G09_FP and 23_G09_RP. PCR product was mixed with the donor plasmid pDONR207 (Invitrogen), and subjected to a recombination reaction with Invitrogen Gateway BP Clonase $^{\mathrm{TM}}$, as described (Legrand et al., 2018), to yield Entry vectors. The recombination mixes were transformed into E. coli Top 10 and one transformant per ORF was selected for further study. The cloned ORFs were sequenced to ascertain that no mutations were introduced during PCR amplification. The Entry plasmids were used in a Gateway ${ }^{\mathrm{TM}} \mathrm{LR}$ reaction together with the CIp10-P $\mathrm{PET}_{\mathrm{TET}} \mathrm{GTW}$ vector (Chauvel et al., 2012). The recombination mixes were transformed into $E$. coli Top10 and one transformant was used for plasmid preparation. BsrGI digestion was used to verify the clones. The expression plasmids were digested by StuI prior to transformation into C. albicans strain CEC4642. Transformants were selected for prototrophy and proper integration at the RPS1 locus verified by PCR using primers CIpUL and CIpUR, as described (Legrand et al., 2018).

\section{Generation of NRG1 deletion mutants}

$N R G 1$ was deleted in isolate 101 using a $S A T 1$-recyclable system (Reuss et al., 2004). Briefly, two primers containing 70-pb of sequences flanking the NRG1 ORF and 20-bp of sequences flanking the SAT1-flipper cassette were used in a PCR with pSFS2A (Reuss et al., 2004) as a template. This step was performed with Phusion DNA Polymerase (New England Biolabs, Ipswich, MA, USA) in the presence of $1 \mathrm{M}$ betaine. The PCR fragment was used to transform the isolate 101 by electroporation (Kannan et al., 2019) and under selection with nourseothricin (400 $\mu \mathrm{g} / \mathrm{ml}$; Werner BioAgents, Jena, Germany). After PCR verification of the first allele deletion by primers pSFS2A Dwn Chk et NRG1_Kpn (isolate DSY5577), the SAT1 marker was recycled as described (Reuss et al., 2004) to yield DSY5592. This last isolate was used for second allele inactivation resulting in DSY5599.

\section{Generation of Tet-off mutant}

To generate NRG1 downregulation in the isolate 101, the tetracycline reversed activator (CartTA) in pNIMX (Chauvel et al., 2012) was replaced after XbaI-MluI digestion by the tetracycline activator reported in Bijlani et al. (Bijlani et al., 2018) to result in pDS2136. The CatTA gene was prepared as a synthetic fragment (Eurofins Genomics GmbH, Ebersberg, Germany). The hygromycin resistance gene (HygR) was amplified with primers Hygro-TEF2Nde et Hygro-ACT1-NdeI using pMY70 (Basso et al., 2010) (see Table S2) and replaced SAT1 as a NdeI fragment in pDS2136 to produce pDS2142. This plasmid was linearized by $\mathrm{KpnI} / \mathrm{SacII}$ for integration at the $A D H 1$ locus in isolate DSY5592 to yield DSY5617 under selection with hygromycin $(600 \mu \mathrm{g} / \mathrm{ml}$; Mediatech, Manassas, VA, USA).

To construct a tetracycline-dependent promoter system, a PCR fusion strategy was chosen. A first fragment containing a tetracycline operator (pTETO7-OP4) was generated with primers Tetp-5 and Tetp-3 using pNIM1 (Chauvel et al., 2012) as template. A second PCR fragment containing the NAT1 dominant marker was generated with overlapping ends using pJK795 (Shen et al., 2005) as template. Both fragments were used in a PCR fusion with primers of 70bp overlapping NRG1 matching regions upstream and downstream of the ORF (NAT1-NRG1 and TetP-3-NRG1). This last step was carried out with Phusion DNA Polymerase (New England Biolabs, Ipswich, MA, USA) in the presence of $1 \mathrm{M}$ betaine. The final PCR fragment was precipitated with $70 \% \mathrm{EtOH}$ and transformed in DSY5617 (NRG1/nrg1 $1:$ :FRT $A D H 1:$ pDS2142) to yield DSY5625 which contains NRG1 under the control of pTETO7-OP4. To test the Tet-off system, a strain with a luciferase reporter system was created by introducing CIp-PTET-SP-gLUC59 after StuI digestion in CEC161 (Chauvel et al., 2012), resulting in isolate DSY5622. Plasmid pDS2142 was next introduced in this isolate to yield DSY5624. 


\section{Luciferase assay}

Isolate DSY5624 was cultured overnight in YEPD and grown to log phase for $4 \mathrm{hr}$ in the same medium $(5 \mathrm{ml})$ containing different Dox concentrations. After incubation, cells were washed and resuspended in $200 \mu \mathrm{l}$ R-luc buffer $\left(\mathrm{NaCl} 0.5 \mathrm{M}, \mathrm{Na}_{2} \mathrm{HPO}_{4} 0.1 \mathrm{M} \mathrm{pH} 7.0\right.$, EDTA $\left.1 \mathrm{mM}\right)$. Eighty $\mu 1$ of each suspension was pipetted in duplicates into black half area 96-well plate. Water-soluble coelenterazine (catalog \# 3032, Nanolight Technology, Pinetop, AZ, USA) was resuspended in $5 \mathrm{~mL}$ PBS (phosphate buffered saline: $137 \mathrm{mM} \mathrm{NaCl}, 2.7 \mathrm{mM} \mathrm{KCl}, 4.3 \mathrm{mM}$ $\mathrm{Na}_{2} \mathrm{HPO}_{4}, 1.47 \mathrm{mM} \mathrm{KH} \mathrm{PO}_{4}$ ) and kept in the dark. Plates were placed in a FLUOstar Omega instrument (BMG Labtech, Champigny/Marne, France). The instrument was kept at a temperature of $30{ }^{\circ} \mathrm{C}$. After shaking the plate for $3 \mathrm{~s}$ and injection of $20 \mu \mathrm{l}$ coelenterazine, reading of luminescence was started and continued with intervals of $1.5 \mathrm{~s}$ for $50 \mathrm{~s}$.

\section{Generation of ECE1 overexpression mutant}

$E C E 1$ was overexpressed in isolate 101 using the $T D H 3$ promoter. The promoter was amplified by PCR using genomic DNA from SC5314 with primer pairs TDH3-XHOI/TDH3KpnI containing KpnI and XhoI sites. After digestion of the PCR fragments by KpnI and XhoI, the promoter was cloned in the plasmid pDS2032 to yield pDS2037. Plasmid pDS2032 contains ECE1 from SC5314 under the control of the HWP1 promoter in the backbone of pDS1904 (Dorsaz et al., 2017), a derivative of CIp10 with a SAT1 dominant marker. The $H W P 1$ promoter and ECE1 were cloned sequentially from PCR fragments obtained with primers pairs HWP1_Kpn/HWP1_XhoI and ECE1_XhoI/ECE1_MluI. Insertion of the KpnIXhoI and XhoI-MluI digested PCR fragments yielded pDS2032. Plasmid pDS2037 was digested by MlscI and SmaI for introduction at the TDH3 loci of isolate 101.

Table S2. Primers used for generating C. albicans mutants

\begin{tabular}{|c|c|}
\hline primer & Sequence (5' -> 3') \\
\hline KO primer fwd NRG1 & $\begin{array}{l}\text { AAACATCGTTATCCTGTTTCTCATCTCAAAATTTTTCCCTGCTAGTTTCATTAAGAATC } \\
\text { AAACAATCATTCTCGAGGAAGTTCCTATACT }\end{array}$ \\
\hline KO primer rev NRG1 & $\begin{array}{l}\text { AAAAAAAACTAAACCCAAGCAATTAACCATCCAAATTTAACCCGTTTTATAATACAAT } \\
\text { TTTGACCACATGTGTGGAATTGTGAGCGGATA }\end{array}$ \\
\hline Psfs2a Dwn Chk & ACAGCGATGTACTGGTACTG \\
\hline NRG1_Kpn & CCAACTAGGGTACCATCATTATAATTAACCCCTC \\
\hline Hygro-TEF2-Nde & CGCGAAACATATGTATAGTGCTTGCTGTTCGA \\
\hline Hygro-ACT1-NdeI & AAGCGCCATATGATTTTATGATGGAATGAATG \\
\hline Tetp-5 & ACTGCTGTCGATTCGATACTAATTAACCCTCACTAAAGGGAACAAAAG \\
\hline Tetp-3 & GATATCGCCATTGTAAATTATTTATA \\
\hline NAT1-3 & CCCTTTAGTGAGGGTTAATTAGTATCGAATCGACAGCAGTATAGCGAC \\
\hline NAT1-5 & CCCTCCTTGACAGTCTTGACGTGCGC \\
\hline NAT1-NRG1 & $\begin{array}{l}\text { GAATCTGAAACAGGTATTATATAAATAACAATAAAACATCGTTATCCTGTTTCTCATC } \\
\text { TC AAAATTTTTCCTGTCGCCCGTACATTTAG }\end{array}$ \\
\hline TetP-3-NRG1 & $\begin{array}{l}\text { AATATAAATAGTCGACAAAGAGTTTCATTAAGAATCAAACAATCATTATGCTTTATCA } \\
\text { AC AATCATATCCAATAACAAATAAGTTATTAA }\end{array}$ \\
\hline HWP1_Kpn & AAAGTGGTACCAAAGCTATGATAAATGTTGATT \\
\hline HWP1_XhoI & ATAATCTCGAGTTGACGAAACTAAAAGCGAGTG \\
\hline ECE1 XhoI & TCCACTCGAGAAAATGAAATTCTCCAAAATT \\
\hline ECE1_MluI & AGAGACGCGTAAGTAAAATATAGGTAATATAAAC \\
\hline TDH3-XHOI & CGCGAACTCGAGTGTTAATTAATTTGATTGTAAAG \\
\hline TDH3-KpnI & GGAACGGTACCATACAGTATTCAGTATGAT \\
\hline 23_G09_FP & $\begin{array}{l}\text { GGGGACAAGTTTGTACAAAAAAGCAGGCTtgATGCTTTATCAACAATCATATCCAATA } \\
\text { ACA }\end{array}$ \\
\hline 23_G09_RP & $\begin{array}{l}\text { GGGGACCACTTTGTACAAGAAAGCTGGGTcTACTAGGCTCTTGGTGTTGTATTTTGTTC } \\
\text { C }\end{array}$ \\
\hline CIpUL & ATACTACTGAAATTTCCTGACTTTC \\
\hline CIpRL & ATTACTATTTACAATCAAAGGTGGTC \\
\hline
\end{tabular}




\section{Keratinocyte cell line and cell culture conditions}

The oral keratinocyte cell line TR146 (Rupniak et al., 1985) was grown in DMEM medium supplemented with $10 \%$ FCS, Penicillin and Streptomycin at $37^{\circ} \mathrm{C}$ and $5 \% \mathrm{CO}_{2}$. For experiments, cells were seeded at $2 \times 10^{5}$ cells/well in 6-well tissue culture plates or at $2 \times$ $10^{4}$ cells/well in 96-well tissue culture plates, respectively, and grown to confluent monolayers for 2 days prior to infection as described below for the individual assays. 1 day prior to the experiment, the DMEM medium was replaced by F12 medium (Hams's Nutrient Mixture F12 medium (Sigma) supplemented with L-Glutamine, Penicillin, Streptomycin, and $1 \%$ FCS).

\section{Reconstituted human epidermis}

Reconstructed human epidermis (RHE) models aged for 17 days were purchased from Episkin and cultured in 6-well tissue culture plates with $2 \mathrm{ml} \mathrm{T-skin} \mathrm{medium} \mathrm{per} \mathrm{well} \mathrm{at} 37^{\circ} \mathrm{C}$ and $5 \% \mathrm{CO}_{2}$. One day prior to infection, the models were transferred from T-skin medium to F12 medium containing 1\% FCS and infected with $4 \times 10^{6}$ yeast cells. The models were then carefully swayed using a sterile forceps to distribute the liquid in the insert. After incubation for $24 \mathrm{~h}$ at $37^{\circ} \mathrm{C}$ and $5 \% \mathrm{CO}_{2}$, the supernatant was collected for cell damage quantification by LDH assay. The models were cut in half and used for RNA isolation and histology, respectively. For histology, the support of the skin reconstructs was detached from the insert with a scalpel prior to embedding the tissue in $4 \%$ paraformaldehyde.

\section{C. albicans growth curve experiments}

C. albicans was inoculated at $\mathrm{OD}_{600}=0.1$ in $200 \mu \mathrm{YPD}$ or the indicated medium in a 96 well plate and grown in an Infinite M200 PRO plate reader (Tecan) for 24 hours at $30^{\circ} \mathrm{C}$ with orbital shaking ( $3 \mathrm{~mm}$ amplitude) and $\mathrm{OD}_{600}$ measurements every 10 minutes.

\section{Morphological analyses}

For assessing filamentation on spider agar (10 g mannitol, $10 \mathrm{~g}$ nutrient broth, $2 \mathrm{~g} \mathrm{~K}_{2} \mathrm{HPO}_{4}$ and $13.5 \mathrm{~g}$ agar per $\left.1 \mathrm{~L} \mathrm{H}_{2} \mathrm{O}\right), 3 \mu \mathrm{l}$ of a yeast cell suspension at $10^{5}$ cells $/ \mathrm{ml}$ were spotted and plates were incubated for 5 days at $30^{\circ} \mathrm{C}$.

For assessing colony shape of SC5314 ${ }^{\mathrm{NRG1}-\mathrm{OE}}$ and SC5314 ${ }^{\mathrm{crz} 2-\mathrm{OE}}, 3 \mu 1$ of a yeast cell suspension at $10^{6}$ cells $/ \mathrm{ml}$ was spotted onto YPD agar containing $10 \% \mathrm{FCS}$ and supplemented with $50 \mu \mathrm{g} / \mathrm{ml}$ Dox and plates were incubated for 2 days at $37^{\circ} \mathrm{C}$. For assessing colony shape of isolates $101^{\mathrm{nrg} 14 \mathrm{NRG} 1}$ and $101^{\mathrm{nrg} / \Delta / \Delta}, 3 \mu \mathrm{l}$ of a yeast cell suspension at $10^{5}$ cells $/ \mathrm{ml}$ was spotted onto Spider agar or YPD agar containing either Glucose or GlcNAc as a carbon source and plates were incubated for 5 days at $30^{\circ} \mathrm{C}$. For measuring filament length, $5 \times 10^{4}$ yeast cells were seeded in F12 medium into 24-well tissue culture plates containing or not containing monolayers of TR146 cells. For analysis of filamentation of $101^{\mathrm{nrg} 1 \mathrm{~A} / \mathrm{pTET}-\mathrm{NRG} 1}, 10 \mu \mathrm{g} / \mathrm{ml}$ Dox was added. After 3.5 - 4 hours of incubation at $37^{\circ} \mathrm{C}$ and $5 \% \mathrm{CO}_{2}$, cells were fixed in $4 \%$ PFA for $30 \mathrm{~min}$ at $4{ }^{\circ} \mathrm{C}$ and washed with PBS. Images were acquired using a Zeiss Axio Observer Z1 inverted phase contrast fluorescence microscope. 4 fields per well were imaged. The length of individual nonaggregated filaments was measured using the ImageJ software.

\section{Invasion assays}

For agar invasion, $5 \mu \mathrm{l}$ of a yeast cell suspension at $10^{7}$ cells $/ \mathrm{ml}$ were spotted on YNB/BSA agar (1.7 g yeast nitrogen base w/o amino acids and ammonium sulphate, $5 \mathrm{~g}$ ammonium sulphate, $20 \mathrm{~g}$ agar, $2 \mathrm{~g} \mathrm{BSA}$ per $1 \mathrm{~L} \mathrm{H}_{2} \mathrm{O}$ ) and incubated for 4 days at $37^{\circ} \mathrm{C}$ and $5 \% \mathrm{CO}_{2}$. Invasion depth was assessed after cutting the agar with a scalpel through the colonies. $\%$ 
bioRxiv preprint doi: https://doi.org/10.1101/2021.10.11.463879; this version posted October 11, 2021. The copyright holder for this

invasion was calculated as the proportion of colony invasion relative to the entire agar thickness.

For assessing invasion of $C$. albicans into TR146 keratinocytes, monolayers of TR146 cells on sterile glass slides in 24-well tissue culture plates prepared as described above were infected with $5 \times 10^{4}$ yeast cells per well. After 3 hours of incubation at $37^{\circ} \mathrm{C}$ and $5 \% \mathrm{CO}_{2}$, cells were fixed in 4\% PFA for 15-30 minutes and subjected to a two-step immunofluorescence staining protocol adapted from Wächtler et al. (Wachtler et al., 2012). Extracellularly fungal parts were stained with an anti-Candida antibody (Meridian Life Science B65411R) followed by AF647-conjugated goat anti-rabbit IgG (Jackson Immunoresearch). After permeabilization with $0,5 \%$ Triton X-100, actin was stained with FITC-labelled phalloidin (Sigma) to visualize epithelial cells and fungal elements were stained with calcofluor white (Sigma). Images were acquired with a Leica SP8 inverse confocal microscope. The $\%$ of invasive hyphae was calculated relative to the total number of hyphae per imaged field.

\section{Phospholipase activity}

$5 \mu 1$ of a yeast cell suspension at $10^{7}$ cells $/ \mathrm{ml}$ were spotted on Prices' original egg yolk agar (4\% glucose, $1 \%$ peptone, $1 \mathrm{M} \mathrm{NaCl}, 2,5 \mathrm{mM} \mathrm{CaCl}_{2}, 17 \mathrm{~g}$ agar per $1 \mathrm{~L}_{2} \mathrm{O}$ and addition of $2,5 \%$ eggyolk (Sigma) after autoclaving) and incubated for 4 days at $37^{\circ} \mathrm{C}$ and $5 \% \mathrm{CO}_{2}$. Phospholipase activity was determined as the ratio of the diameter of the colony relative to the diameter of the precipitation zone forming around the colony.

\section{Cell damage assay}

Damage induction by C. albicans in TR146 cells was performed as described (Wachtler et al., 2011). Briefly, monolayers of TR146 cells in 96-well tissue culture plates prepared as described above were infected with $2 \times 10^{4}$ yeast cells per well and incubated for 24 hours at $37^{\circ} \mathrm{C}$ and $5 \% \mathrm{CO}_{2}$. Control wells were incubated with medium only or with $1 \%$ Triton-X-100 to determine $100 \%$ damage. LDH release into the supernatant was quantified with the LDH cytotoxicity kit (Roche) according to the manufacturer's instructions. For assessing LDH concentrations in the supernatant of reconstructed human epidermis, a standard curve was generated with recombinant LDH enzyme.

\section{Cytokine quantification by ELISA}

IL-6, IL-8, and GM-CSF levels in the supernatant of infected TR146 monolayers and RHE models were quantified by ELISA using cytokine-specific DuoSet ELISA systems (R\&D Systems) according to the manufacturer`s instructions.

\section{Mice}

Female WT C57BL/6j mice were purchased from Janvier Elevage and maintained at the Laboratory Animals Service Center of the University of Zurich under specific pathogen-free conditions. Mice were used at 6-15 weeks of age in age-matched groups. Infected and uninfected animals were kept separately to avoid cross-contamination.

\section{Ethics Statement}

All mouse experiments in this study were conducted in strict accordance with the guidelines of the Swiss Animals Protection Law and were performed under the protocols approved by the Veterinary office of the Canton of Zürich, Switzerland (license number 183/2015 and 166/2018). All efforts were made to minimize suffering and ensure the highest ethical and humane standards according to the $3 \mathrm{R}$ principles. 


\section{OPC infection model}

Mice were infected sublingually with $2.5 \times 10^{6}$ C. albicans yeast cells as described (Solis and Filler, 2012), without immunosuppression. In co-infection experiments, mice were infected with $1.25 \times 10^{6}$ yeast cells of each isolate, resulting in a total of $2.5 \times 10^{6}$ yeast cells. In 7-day experiments, the body weight of the animals was assessed prior and during the course of infection. For experiments with Dox -inducible $C$. albicans isolates, mice were administered Dox in the drinking water $(2 \mathrm{mg} / \mathrm{ml})$ starting from 1 day prior of infection. For determination of the fungal burden, the tongue of euthanized animals was removed, homogenized in sterile $0.05 \% \mathrm{NP} 40$ in $\mathrm{H}_{2} \mathrm{O}$ for 3 minutes at $25 \mathrm{~Hz}$ using a Tissue Lyzer (Qiagen) and serial dilutions were plated on YPD agar containing $100 \mu \mathrm{g} / \mathrm{ml}$ Ampicillin. For histology, tissue was fixed in 4\% PBS-buffered paraformaldehyde overnight and embedded in paraffin. Sagittal sections $(9 \mu \mathrm{m})$ were stained with Periodic-acidic Schiff (PAS) reagent and counterstained with Haematoxilin and mounted with Pertex (Biosystem) according to standard protocols. Images were acquired with a digital slide scanner (NanoZoomer 2.0-HT, Hamamatsu) and analysed with NDP.view2.

\section{Isolation of C. albicans from infected tongue tissue}

Longitudinally cut tongue halves were placed into $1.5 \mathrm{ml}$ safe-lock tubes containing $800 \mathrm{ml}$ sterile $20 \% \mathrm{KOH}$ solution and incubated at $60^{\circ} \mathrm{C}$ and $300 \mathrm{rpm}$ for at least 30 minutes. Tubes were inverted regularly to prevent sedimentation of tissue fragments. After complete dissolution of the tissue, the suspension was centrifuged for 10 minutes at 6'000 rpm and supernatant was discarded. C. albicans cells were suspended in $495 \mu 1$ Tris- $\mathrm{HCl}(0.1 \mathrm{M}, \mathrm{pH}$ 9) and $5 \mu \mathrm{l}$ calcofluor white $(5-10 \mathrm{mg} / \mathrm{ml}$ in $0.1 \mathrm{M}$ Tris- $\mathrm{HCl}, \mathrm{pH} 9)$ to stain the cell wall. After 10 minutes of incubation in the dark, $C$. albicans cells were sedimented for 10 minutes at 6'000rpm and washed twice with $1 \mathrm{ml}$ Tris- $\mathrm{HCl}(0.1 \mathrm{M}, \mathrm{pH}$ 9). Fungal cell pellets were then resuspended in $20 \mu \mathrm{PBS}$ and images with a Leica SP8 inverse confocal microscope.

\section{Quantification of tongue neutrophils and inflammatory monocytes by flow cytometry}

Mice were anesthetized with a sublethal dose of Ketamine (100 mg/kg, Streuli), Xylazin (20 $\mathrm{mg} / \mathrm{kg}$, Streuli), and Acepromazin $(2.9 \mathrm{mg} / \mathrm{kg}$, Fratro S.p.A.) and perfused by injection of PBS into the right heart ventricle prior to removing the tongue. Tongues were cut into fine pieces and digested with DNase I ( $200 \mu \mathrm{g} / \mathrm{ml}$, Roche) and Collagenase IV $(4.8 \mathrm{mg} / \mathrm{ml}$, Invitrogen) in PBS at $37^{\circ} \mathrm{C}$ for $45-60 \mathrm{~min}$. Single cell suspensions were passed through a 70 $\mu \mathrm{m}$ strainer and stained in ice-cold PBS supplemented with $1 \%$ FCS, 5 mM EDTA, and $0.02 \%$ NaN3 with LIVE/DEAD Fixable Near-IR Stain (Life Technologies) and fluorochrome-conjugated antibodies against mouse CD45.2 (clone 104), CD11b (clone M1/70) and Ly6G (clone 1A8); Ly6C (clone AL-21). All antibodies were from BioLegend. Stained cells were analysed on a FACS Gallios (Beckman Coulter), or a SP6800 Spectral Analyzer (Sony). The data were analysed with FlowJo software (FlowJo LLC). The gating of the flow cytometric data was performed according to the guidelines for the use of flow cytometry and cell sorting in immunological studies (Cossarizza et al., 2019). including pregating on viable and single cells for analysis. Absolute cell numbers of lymphocyte populations were calculated based on a defined number of counting beads (BD Bioscience, Calibrite Beads), which were added to the samples before flow cytometric acquisition.

\section{C. albicans killing by neutrophils}

Hyphae were pre-formed by incubating 5'000 C. albicans yeast cells per well in a 96-well tissue culture plate in HBSS supplemented with 5\% FCS for 3 hours. Neutrophils were isolated from the bone marrow of naïve C57BL/6j mice as described (Guiducci et al., 2018) 
bioRxiv preprint doi: https://doi.org/10.1101/2021.10.11.463879; this version posted October 11,2021 . The copyright holder for this preprint (which was not certified by peer review) is the author/funder, who has granted bioRxiv a license to display the preprint in perpetuity. It is made available under aCC-BY 4.0 International license.

and added at different concentrations to the preformed hyphae (4 wells per condition). Neutrophils alone were used as background controls. Amphotericin B $(10 \mu \mathrm{g} / \mathrm{ml})$ served as a positive control for fungal killing. After 4 hours of incubation at $37^{\circ} \mathrm{C}$ and $5 \% \mathrm{CO}_{2}$ neutrophils were lysed by addition of $0,01 \%$ Triton X-100 in $\mathrm{H}_{2} \mathrm{O}$, washed with PBS and suspended in $100 \mu 1$ PBS per well PBS. After addition of $10 \mu \mathrm{l}$ WST-1 cell Proliferation Reagent (Roche) cells were incubated for $1 \mathrm{~h}$ at $37^{\circ} \mathrm{C}$ before absorbance was measured at 450 $\mathrm{nm}$ with a wavelength correction set at $620 \mathrm{~nm}$. A standard curve was generated with a serial dilution of each C. albicans isolate starting from 10'000 cells to extrapolate the number of viable $C$. albicans from the determined absorbance reflecting metabolic activity.

\section{Preparation of tongue epithelial sheets and isolation of RNA for RNAseq}

Epithelial sheets were prepared from infected tongues as described (Kirchner et al., 2019). Briefly, the tongue was cut in half to obtain the dorsal part, which was freed from muscle tissue with a scalpel and floated on PBS containing $2.86 \mathrm{mg} / \mathrm{ml}$ dispase II (Roche) for 60min with the epithelial side facing upwards to separate the epithelial tissue from the lamina propria. Epithelial sheets were incubated in RNA-later (Sigma) for 1 min immediately after isolation. Three epithelial sheets were pooled per replicate, two replicates were generated for each condition.

For 'in vitro' samples, C. albicans hyphae were induced for 9 hours, harvested using a cell scraper, washed in PBS and rinsed in RNA-later. Two replicates were generated for each condition.

For RNA isolation, epithelial sheets and hyphae pellets were grinded in liquid $\mathrm{N}_{2}$ and processed as described before (Amorim-Vaz et al., 2015a) combining two phase separations and DirectZol ${ }^{\mathrm{TM}}$ RNA MiniPrep kit (Zymo Research). DNase treatment was performed offcolumn using a DNA-free ${ }^{\mathrm{TM}} \mathrm{Kit}$ (Life Technologies). RNA integrity was determined using a 2100 Bioanalyzer system (Agilent Technologies). RNA was denatured at $70^{\circ} \mathrm{C}$ for $2 \mathrm{~min}$ prior to analysis. Samples were only included if the RNA integrity value (RIN) was above 7.5 or if two clear peaks for $18 \mathrm{~S}$ and $25 \mathrm{~S} / 28 \mathrm{~S}$ rRNA were present and no obvious degradation was observed.

\section{Preparation of cDNA Libraries and Sequencing}

cDNA libraries were generated using SureSelectXT multiplexed sequencing kit with RNA target enrichment for Illumina according to the manufacturer's instructions. In brief, mRNA was purified using poly(A) beads, fragmented, and double-stranded cDNA with ligated adapters was generated. The library was amplified using primers that match the adapters. $C$. albicans specific sequences were enriched using a hybridization technology based on biotinylated baits that cover 6'094 C. albicans ORFs but only a negligible fraction of mouse and human cDNA sequences from Ensembl, designed to specifically capture C. albicansderived cDNA (Amorim-Vaz et al., 2015b). Amplified libraries were incubated with biotinylated baits at $65^{\circ} \mathrm{C}$ for $24 \mathrm{~h}$, and hybridized sequences were collected using magnetic streptavidin beads. The collected double-strand cDNA was then amplified and indexed in a separate PCR. For the analysis of RNA-seq samples from in vitro induced hyphae, $1 \%$ of RNA was used to spike RNA samples from naive mice, which were then subjected to the same enrichment procedure described above. RNA quality, fragment size and cDNA concentration were determined using a fragment analyzer automated CE system (Advanced Analytical) and a Qubit fluorometer (Invitrogen).

\section{RNA-Seq Data Analysis}


The sequencing was performed by Lausanne Genomic Technologies Facility (LGTF). cDNA libraries were subjected to cluster generation using the Illumina TruSeq PE cluster kit v3 reagents and sequenced on the Illumina HiSeq 2500 system with TruSeq SBS kit v3 reagents. Sequencing data were processed analogous to a previous study (Amorim-Vaz et al., 2015b): Data were processed using Illumina Pipeline software (v1.82). Purity-filtered reads were adapters- and quality-trimmed with Cutadapt (v1.2.1) (Martin, 2011) and filtered for low complexity with Prinseq (v0.20.3) (Schmieder and Edwards, 2011). After alignment against the Candida albicans genome SC5314 version A21-s02- m09-r07 using STAR (v2.5) (Dobin et al., 2013; Kim et al., 2013), htseqcount (v0.5.4p3) was used to summarize the number of read counts per gene locus (Anders et al., 2015). Genes with counts fewer than one per million in all samples were removed from the statistical analysis. Data normalization and differential expression analysis were performed in R (v3.2.2), using Bioconductor packages. Normalization of read count data was performed with the R package edgeR using the TMM (trimmed mean of M-values) method (Robinson and Oshlack, 2010). Normalized read count data was transformed to $\log 2$ counts per million by voom (implemented in the R package limma) (Law et al., 2014). The hierarchical clustering and principal component analysis were done in $\mathrm{R}$ (v3.2.2).

A linear model was built on the transformed data from the following conditions: SC_in_vitro, SC_d1, 101_in_vitro, 101_d1, 101_d3, and 101_d7 (all in duplicates). Differential expression analysis was then performed on the linear model with multiple contrasts representing the differences: (i) between the 101_in_vitro and SC_in_vitro conditions; (ii) between the 101_d1/3/7 conditions and the SC_ $\overline{\mathrm{d}} 1$ condition; (iii) between the 101 d $3 / 7$ conditions and the 101 d 1 condition. P-values produced from the differential analysis were adjusted using the Benjamini \& Hochberg correction (Benjamini and Hochberg, 1995), and adjusted pvalues $($ FDR $)<0.05$ were considered significant. Heatmaps were generated with GENE-E (Broad Institute). GO process enrichment analysis was performed with the GO term finder integrated in the Candida Genome Database. The Gene Ontology (GO) term enrichment analysis was performed using DAVID Bioinformatics Resources 6.8 (NIAID, NIH). The enriched GO terms were hierarchically clustered with the semantic similarity between GO terms based on the graph structure of GO (Wang measure) using the R package GOSemSim (v2.12.1) (Yu et al., 2010) and plotted with the R package ComplexHeatmap (v2.2.0) (Gu et al., 2016).

Transcriptomic data are deposited on the NCBI BioProject [number will be provided upon acceptance of the manuscript].

\section{Isolation of fungal RNA from infected keratinocyte monolayers}

Monolayers of TR146 cells in 24-well tissue culture plates prepared as described above were infected with $4 \times 10^{4}-10^{5}$ yeast cells per well. In case of infection with Dox -inducible isolates, $50 \mu \mathrm{g} / \mathrm{ml}$ (in case of SC5314 ${ }^{\mathrm{NRG1}-\mathrm{OE}}$ and SC5314 ${ }^{\mathrm{crz} 2-\mathrm{OE}}$ ) or $10 \mu \mathrm{g} / \mathrm{ml}$ Dox (in case of $101 \mathrm{nrg} 14 / \mathrm{pTET}$-NRG1 , unless stated otherwise) was added. After $24 \mathrm{~h}$ of incubation at $37^{\circ} \mathrm{C}$ and $5 \% \mathrm{CO}_{2}$, RNA was isolated with the RNeasy® Mini Kit (Quiagen). Briefly, the cells were lyzed in RLT lysis buffer and homogenized with $0.5 \mathrm{~mm}$ glass beads (Sigma) using a Tissue Lyzer (Qiagen) 7 times for 2 minutes at $30 \mathrm{~Hz}$ interrupted by $30 \mathrm{sec}$ cooling periods on ice. Cell debris were removed by centrifugation. One volume of $75 \%$ ethanol was admixed, and each sample was transferred to a RNeasy spin column. The loaded columns were washed using RW1 buffer and RPE buffer. RNA was eluted in $30 \mu \mathrm{l}$ RAse-free water.

\section{Isolation of host RNA from infected TR146 cells and RHE}

Host cell RNA was isolated with TRIZOL according to the manufacturer's instructions. 


\section{$R T-q P C R$}

cDNA was generated by RevertAid reverse transcriptase (Thermo Fisher) and random nonamers. RT-qPCR was performed using SYBR Green (Roche) and a QuantStudio 7 Flex (Life Technology) instrument. All RT-qPCR assays were performed in duplicates and the relative expression levels of each gene was determined by normalization to the housekeeping gene. $h G 6 P D$ was used as housekeeping gene in human and EFB1 or $A C T 1$ in C. albicans, respectively. Using $E F B 1$ or $A C T 1$ as a housekeeping gene provided comparable results. The primers used to detect human transcripts are listed in Table S3, those to detect fungal transcripts are listed in Table S4.

Table S3. Primers for detecting host transcripts

\begin{tabular}{|c|c|c|}
\hline Gene & Forward primer (5' -> 3') & Reverse primer (5' $\left.\rightarrow>3^{\prime}\right)$ \\
\hline$h G 6 P D$ & ATCGACCACTACCTGGGCAA & TTCTGCATCACGTCCCGGA \\
\hline$h I L-6$ & TCTGGATTCAATGAGGAGACTTG & CAGGAACTGGATCAGGACTTTTG \\
\hline$h I L-8$ & CAAGAGCCAGGAAGAAACCA & GTCCACTCTCAATCACTCTCAG \\
\hline$m A c t b$ & CCCTGAAGTACCCCATTGAAC & CTTTTCACGGTTGGCCTTAG \\
\hline$m I l 1 b$ & CAACCAACAAGTGATATTCTCCAT & GATCCACACTCTCCAGCTGCA \\
\hline$m I l 17 a$ & GCTCCAGAAGGCCCTCAGA & AGCTTTCCCTCCGCATTGA \\
\hline$m S 100 a 9$ & GTCCAGGTCCTCCATGATGT & TCAGACAAATGGTGGAAGCA \\
\hline mIl6 & GAGGATACCACTCCCAACAGACC & AAGTGCATCATCGTTGTTCATACA \\
\hline$m \operatorname{Tnf}$ & CATCTTCTCAAAATTCGAGTGACAA & TGGGAGTAGACAAGGTACAACCC \\
\hline
\end{tabular}

Table S4. Primers for detecting C. albicans transcripts ${ }^{1}$

\begin{tabular}{|c|c|c|}
\hline Gene & Forward primer (5' -> 3') & Reverse primer (5' -> 3') \\
\hline EFB1 & CATTGATGGTACTACTGCCAC & TTTACCGGCTGGCAAGTCTT \\
\hline$A C T 1$ & TGCTGAACGTATGCAAAAGG & TGAACAATGGATGGACCAGA \\
\hline NRG1 & AACCTCAGCCATACCATCAAC & GTAATTAGCCCTGGAGATGGTC \\
\hline ECE1 & CCAAAATTGCCTGTGCTACTG & CTCTTCATGTTGAATTCTGGAGC \\
\hline$A L S 3$ & GGTCTCAATCCTATACCACTGC & GGTTGGTGTAATGAGGACGAG \\
\hline$H W P 1$ & CGGAATCTAGTGCTGTCGTCTCT & CCTTCAAATGTAGAAATAGGAGCAAC \\
\hline SAP6 & ACTGGGTCTTCTGATTTGTGG & GCAGCTGGAGAATAAGAACCG \\
\hline$P G A 25$ & TTGTCGGATCTTTTCCCTGG & ATCCTCTTCAGCACTGGAAC \\
\hline$C R Z 2$ & ACTTCTTCAGCCACGTCATC & CATGCAGTCGAGCAAATCGT \\
\hline XOG1 & CGACCACATTTCAGTTGCTTG & AGCATTATCGTAAGCACCCTC \\
\hline PFK1 & TTGAGACACAGAGAATATGGTAGAAG & CTTCTGAAGTGATTGGGTTCAATT \\
\hline PFK2 & CACCCCTAACGAATTGTACCC & CTGGCTTAGGGTGGGATTTT \\
\hline$F D H 1$ & GCTAAAGCTCCCAAATTGAAGC & ATGGCAGCGATACCTCTTTC \\
\hline$S A P 2$ & GGGTTCCTGATGTTAATGTTGATTG & GAAACACCACCAAATCCAACG \\
\hline
\end{tabular}

${ }^{1}$ All primers for $C$. albicans transcripts were designed to bind to sequences that are conserved between isolates SC5314 and 101.

\section{Statistical analysis}

Statistical significance was determined by two-tailed unpaired Student's t-test, one- or twoway ANOVA as appropriate using GraphPad Prism 6.0 (GraphPad Software Inc., La Jolla, CA) with *P $0.05 ; * * \mathrm{P} 0.01$; ***P $0.001 ; * * * * \mathrm{P} 0.0001$.

\section{ACKNOWLEDGMENTS}

The authors would like to thank Noëmi Küng for help with experiments, Françoise Ischer and Danielle Brandalise for technical help with generating C. albicans mutants; Ilse Jacobsen for sharing the $\mathrm{KOH}$ protocol; the Laboratory Animal Service Center of University of Zürich for animal care; the Laboratory Animal Model Pathology of University for histology; the Lausanne Genomic Technologies Facility of University of Lausanne for RNA sequencing; and members of the LeibundGut-lab for discussions. 


\section{AUTHOR CONTRIBUTIONS}

Conceptualization: CL, SA, SLL; Data curation: VDTT; Formal analysis: CL, KMSV, RFM, SA, SLL; Funding Acquisition: SLL, DS, MP; Investigation: CL, KMSV, RFM, SA, SV; Resources: LSR, CdE; Supervision: DS, SLL; Validation: SLL; Visualization: DS, VDTT, SLL; Writing (original draft): CL, SLL; Writing (review \& editing): all authors.

\section{LEGENDS}

Figure 1: C. albicans isolate 101 displays reduced filamentation compared to SC5314 A.-B. C57BL/6 WT mice were infected sublingually with isolate 101 or SC5314. Histology images in A depict PAS-stained tongue sections on day 1 post-infection. Scale bar $=250 \mu \mathrm{m}$. Arrows point to fungal elements. Fungal elements isolated at the same time point by $\mathrm{KOH}$ were visualized with calcofluor white in B. Scale bar $=20 \mu \mathrm{m}$. Data are representative of at least 2 independent experiments.

C.-H. C. albicans isolates 101 and SC5314 were grown for 3-4 hour in F12 medium (C-E) or on top of a monolayer of TR146 cells in F12 medium (F-H). Representative microscopy images are shown in $\mathbf{C}$ and $\mathbf{E}$. Scale bar $=100 \mu \mathrm{m}$. Framed areas are magnified in the bottom left corner. Panels $\mathbf{D}$ and $\mathbf{G}$ show quantification of filament length. Each dot represents an independent hyphal element; the mean $\pm \mathrm{SD}$ is indicated. In $\mathbf{E}$ and $\mathbf{H}$, fungal elements were grouped according to their length and the proportion of fungal elements in each group is shown. Data are representative of at least 3 independent experiments for each condition. G. Representative image of isolates 101 and SC5314 grown on Spider agar for 5 days at $30^{\circ} \mathrm{C}$.

\section{Figure 2: Isolate 101 is less invasive than SC5314}

A. Representative images (left) and quantification (right) of the invasion depth of isolates 101 and SC5314 in YNB agar supplemented with BSA after 7 days of incubation at $37^{\circ} \mathrm{C}$ and $5 \%$ $\mathrm{CO}_{2} \%$. Agar invasion was calculated as the \% of invasion depth (dotted arrow) relative to the overall thickness of the agar (solid arrow). Data were pooled from 4 independent experiments with 2-3 samples each. The mean \pm SEM is indicated. Similar results were obtained with YNB agar supplemented with glucose or casamino acids.

B. Representative images (left) and quantification (right) of TR146 cell monolayers incubated with isolate 101 or SC5314 for 4 hours at $37^{\circ} \mathrm{C}$ and $5 \% \mathrm{CO}_{2}$. Extracellular fungal parts were stained with an anti-Candida antibody (red), full fungal elements were visualized by calcofluor white staining (blue), and keratinocytes were stained with phalloidin (green). Each symbol is the \% invasion per field analysed with an average of 8 hyphae per field (a total of 32 fields were analysed per isolate with 234 hyphae for SC5314 and 290 hyphae for 101). The mean $\pm \mathrm{SEM}$ is indicated for each group. Data were pooled from 2 independent experiments.

C.-E. Reconstituted human epidermis (RHE) was infected with isolate 101 or SC5314 (bottom) for 24 hours. C shows PAS-stained histology sections. Scale bar $=250 \mu \mathrm{m}$. Cellular damage was assessed by LDH release assay in $\mathbf{D}$, GM-CSF concentrations were determined in the supernatant by ELISA in E, and IL-6 and IL-8 transcript levels were quantified by RTqPCR in F. Bars are the mean + SD of $4(\mathbf{D}, \mathbf{E})$ or $2(\mathbf{F})$ replicate wells.

G.-H. Monolayers of TR146 keratinocyte were infected with isolate 101 or SC5314 for 24 hours. Epithelial cell damage was assessed by LDH release assay in $\mathbf{G}$, and IL-6 and IL-8 
bioRxiv preprint doi: https://doi.org/10.1101/2021.10.11.463879; this version posted October $11,2021$. The copyright holder for this preprint (which was not certified by peer review) is the author/funder, who has granted bioRxiv a license to display the preprint in perpetuity. It is made available under aCC-BY 4.0 International license.

cytokine levels were quantified in the supernatant by ELISA in H. Bars are the mean+SD of 4 replicate wells. Data are representative of at least 2 independent experiments.

\section{Figure 3: Isolate 101 persists in the oral mucosa even in presence of SC5314-induced inflammation}

A-C. C57BL/6 WT mice were infected sublingually with a 1:1 mixture of isolates 101mCherry (101-mCh) and SC5314-GFP (SC-GFP) or with either isolate alone. On day 1 (A) and on day $7(\mathbf{C})$ the total tongue fungal burden was quantified (left panels). From the coinfected animals, the colonies were further analysed for mCherry- and GFP-expression (right panels). Quantification of tongue-infiltrating neutrophils by flow cytometry on day 1 postinfection is shown in $\mathbf{B}$. Each symbol represents one animal. The mean of each group is indicated. Data in A and B are pooled from 2, data in C are pooled from 3 independent experiments. d.1., detection limit.

Please see also Figure S1.

\section{Figure 4: Persistence of isolate 101 in the oral mucosa is associated with a reduced virulence profile and an altered metabolic signature.}

A. PCA plot generated from the 5589 C. albicans genes that were detected in the RNAseq analysis.

B-C. Venn diagram showing the GO terms associated with genes that were down-regulated (B) or up-regulated (C) in isolate 101 on day 1, day 3 and/or day 7 post-infection in comparison to SC5314 on day 1 post-infection. Only genes with p-values below 0.05 and $\log 2$ fold change $\geq 1$ and $\leq-1$ were considered.

D. Heat map of selected differentially regulated genes linked to virulence, morphogenesis, cell wall and metabolism $(\mathrm{p}<0.05)$. Genes are displayed by decreasing $\log 2$ fold-change for the 'in vitro' condition (101 in vitro vs. SC5314 in vitro). d1, 101 in vivo day 1 vs. SC5314 in vivo day 1; d3, 101 in vivo day 3 vs. SC5314 in vivo day 1; d7, 101 in vivo day 7 vs. SC5314 in vivo day 1 .

Please see also Figure S2 and Figure S3.

Figure 5: Overexpression of NRG1 in SC5314 restrains its virulence potential in vitro and in vivo

A. Monolayers of TR146 keratinocytes were infected with SN76 ${ }^{\mathrm{NRG1}-O E}$ or SN76 ${ }^{\mathrm{CTRL}}$ and treated with Dox or left untreated. RNA was isolated 24 hours post-infection and expression of $N R G 1$ was assessed by RT-qPCR. Bars are the mean+SD of 3 samples per conditions, representative of 2 independent experiments.

B-C. Morphology of SN76 ${ }^{N R G 1-O E}$ and SN76 ${ }^{\mathrm{CTRL}}$ in presence or absence of Dox on YPD agar for 2 days (top) or in F12 medium for 8 hours (bottom). Data in C are representative of 2 independent experiments with 3-6 replicates per condition. The same results were obtained with two independent clones of SN76 ${ }^{N R G 1-\mathrm{OE}}$.

D. Expression of the indicated genes were assessed as in (A).

E. Monolayers of TR146 keratinocyte were infected with isolates SN76 ${ }^{\text {NRGI-OE }}$ or SN76 ${ }^{\mathrm{CTRL}}$ in presence or absence of Dox and epithelial cell damage was assessed after 24 hours of infection by LDH release assay. Bars are the mean+SEM of 8 samples per condition pooled from 2 independent experiments. The same results were obtained with two independent

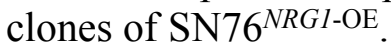

F.-J. C57BL/6 WT mice were infected sublingually with isolates SN76 ${ }^{N R G 1-O E}$ or SN76 ${ }^{\mathrm{CTRL}}$ and treated or not with Dox. Fungal burden was assessed after 1 day (F) or 3 days of infection (I). Tongue sections were stained with PAS (G) and neutrophils in the tongue were quantified by flow cytometry $(\mathbf{H})$ on day 1 post-infection. Weight loss and re-gain relative to 
the pre-infection weight is shown in $(\mathbf{J})$. In F, H and I, each symbol represents one animal, data are pooled from two independent experiments; in $\mathrm{J}$ each symbol is the mean $\pm \mathrm{SD}$ of 4 animals; images shown in $\mathrm{G}$ are representative of 2 independent experiments. Please see also Figure S4.

\section{Figure 6: Reduced expression of NRG1 in isolate 101 increases its pathogenicity}

A.-D. Monolayers of TR146 keratinocytes were infected with isolates $101^{\text {nrgl } 14 \mathrm{NRG} 1 \text {, }}$ $101^{\text {nrg14/4 }}$, the parental isolate 101 and strain SC5314. Expression of the indicated fungal genes was assessed by RT-qPCR after 24 hours of infection $(\mathbf{A}, \mathbf{B})$. Bars are the mean+SD of 3 samples per condition. Filamentation was assessed after 3.5 hours of infection by measuring the length of individual filaments $(\mathbf{C}$, left). Each dot represents an independent hyphal element; the mean \pm SD is indicated. Fungal elements were grouped according to their length and the proportion of fungal elements in each group is shown $(\mathbf{C}$, right). Data are representative of 3 independent experiments (only one experiment for $101^{\mathrm{nrg} / \Delta / \Delta}$ ). Epithelial cell damage was assessed by LDH release assay at 24 hours post-infection (D). Bars are the mean + SEM of $10-22$ samples per group pooled from 2-3 independent experiments. E.-J. C57BL/6 WT mice were infected sublingually with isolates $101^{\text {nrgl } 14 \mathrm{NRG} 1}$, the parental isolate 101 and SC5314. Fungal burden was assessed after 1 day (E) or 7 days of infection (I). Neutrophils and monocytes in the tongue were quantified by flow cytometry (F) and tongue sections were stained with PAS $(\mathbf{G})$ on day 1 post-infection. The indicated host transcripts in the tongue were quantified by RT-qPCR on day $1(\mathbf{H})$ or day 7 post-infection (J). In E, F, H, I and J, each symbol represents one animal; the mean is indicated. Data in E and $\mathrm{F}$ are pooled from 3 independent experiments.

Please see also Figure S5.

\section{Figure 7: Suppression of NRG1 expression in isolate 101 via a TET-off strategy drives fungal pathogenicity}

A.-B. Monolayers of TR146 keratinocytes were infected with isolates $101^{\text {nrgl } 1 / \mathrm{pTET}-N R G 1}$ in presence or absence of $10 \mu \mathrm{g} / \mathrm{ml}$ Dox and with SC5314. Expression of the indicated fungal genes was assessed by RT-qPCR after 24 hours of infection. Bars are the mean+SD of 3 samples per condition.

C. $101^{\text {nrgl } 1 / \mathrm{pTET}-N R G 1}$ yeast cells were grown for 4 hours at $37^{\circ} \mathrm{C}$ in YPD with or without addition of $10 \mu \mathrm{g} / \mathrm{ml}$ Dox.

D. Monolayers of TR146 keratinocytes were infected with isolate $101^{\text {nrg1 } 1 / \mathrm{pTET} \text { TRRG1 }}$ in presence or absence of $10 \mu \mathrm{g} / \mathrm{ml}$ Dox. Filamentation was assessed after 3.5 hours of infection by measuring the length of individual filaments (left). Each dot represents an independent hyphal element; the mean \pm SD is indicated. Fungal elements were grouped according to their length and the proportion of fungal elements in each group is shown (right).

E. Epithelial cell damage was assessed by LDH release assay at 24 hours post-infection. Bars are the mean+SEM of $10-16$ samples per group pooled from 2 independent experiments.

F.-G. C57BL/6 WT mice were infected sublingually with isolate $101^{\text {nrg } 14 / \text { pTET-NRG1 }}$ or SC5314 for 1 day. Fungal burden was assessed in F. Neutrophils and monocytes in the tongue were quantified by flow cytometry in $\mathbf{G}$. Each symbol represents one animal; the mean is indicated. Data are pooled from 2 independent experiments.

Please see also Figure S6. 


\section{REFERENCES}

Abbey, D., Hickman, M., Gresham, D., and Berman, J. (2011). High-Resolution SNP/CGH Microarrays Reveal the Accumulation of Loss of Heterozygosity in Commonly Used Candida albicans Strains. G3 (Bethesda) 1, 523-530.

Allert, S., Forster, T.M., Svensson, C.M., Richardson, J.P., Pawlik, T., Hebecker, B., Rudolphi, S., Juraschitz, M., Schaller, M., Blagojevic, M., et al. (2018). Candida albicansInduced Epithelial Damage Mediates Translocation through Intestinal Barriers. mBio 9.

Altmeier, S., Toska, A., Sparber, F., Teijeira, A., Halin, C., and LeibundGut-Landmann, S. (2016). IL-1 Coordinates the Neutrophil Response to C. albicans in the Oral Mucosa. PLoS pathogens 12 , e1005882.

Amorim-Vaz, S., Delarze, E., Ischer, F., Sanglard, D., and Coste, A.T. (2015a). Examining the virulence of Candida albicans transcription factor mutants using Galleria mellonella and mouse infection models. Front Microbiol 6, 367.

Amorim-Vaz, S., Tran Vdu, T., Pradervand, S., Pagni, M., Coste, A.T., and Sanglard, D. (2015b). RNA Enrichment Method for Quantitative Transcriptional Analysis of Pathogens In Vivo Applied to the Fungus Candida albicans. MBio 6, e00942-00915.

Anders, S., Pyl, P.T., and Huber, W. (2015). HTSeq--a Python framework to work with highthroughput sequencing data. Bioinformatics 31, 166-169.

Barelle, C.J., Manson, C.L., MacCallum, D.M., Odds, F.C., Gow, N.A., and Brown, A.J. (2004). GFP as a quantitative reporter of gene regulation in Candida albicans. Yeast 21, 333340.

Basso, L.R., Jr., Bartiss, A., Mao, Y., Gast, C.E., Coelho, P.S., Snyder, M., and Wong, B. (2010). Transformation of Candida albicans with a synthetic hygromycin B resistance gene. Yeast 27, 1039-1048.

Battistone, G.C., and Burnett, G.W. (1961). The free amino acid composition of human saliva. Arch Oral Biol 3, 161-170.

Benjamini, Y., and Hochberg, Y. (1995). Controlling the False Discovery Rate: A Practical and Powerful Approach to Multiple Testing. Journal of the Royal Statistical Society. Series B (Methodological) 57, 289-300.

Berman, J. (2016). Ploidy plasticity: a rapid and reversible strategy for adaptation to stress. FEMS Yeast Res 16.

Bijlani, S., Nahar, A.S., and Ganesan, K. (2018). Improved Tet-On and Tet-Off systems for tetracycline-regulated expression of genes in Candida. Curr Genet 64, 303-316.

Bohm, L., Torsin, S., Tint, S.H., Eckstein, M.T., Ludwig, T., and Perez, J.C. (2017). The yeast form of the fungus Candida albicans promotes persistence in the gut of gnotobiotic mice. PLoS pathogens 13, e1006699.

Braun, B.R., Kadosh, D., and Johnson, A.D. (2001). NRG1, a repressor of filamentous growth in C.albicans, is down-regulated during filament induction. EMBO J 20, 4753-4761.

Calderone, R.A., and Clancey, S.A. (2012). Candida and candidiasis, 2nd edn (ASM Press).

Candi, E., Schmidt, R., and Melino, G. (2005). The cornified envelope: a model of cell death in the skin. Nat Rev Mol Cell Biol 6, 328-340. 
Chauvel, M., Nesseir, A., Cabral, V., Znaidi, S., Goyard, S., Bachellier-Bassi, S., Firon, A., Legrand, M., Diogo, D., Naulleau, C., et al. (2012). A versatile overexpression strategy in the pathogenic yeast Candida albicans: identification of regulators of morphogenesis and fitness. PLoS One 7, e45912.

Conti, H.R., Shen, F., Nayyar, N., Stocum, E., Sun, J.N., Lindemann, M.J., Ho, A.W., Hai, J.H., Yu, J.J., Jung, J.W., et al. (2009). Th17 cells and IL-17 receptor signaling are essential for mucosal host defense against oral candidiasis. J Exp Med 206, 299-311.

Cossarizza, A., Chang, H.D., Radbruch, A., Acs, A., Adam, D., Adam-Klages, S., Agace, W.W., Aghaeepour, N., Akdis, M., Allez, M., et al. (2019). Guidelines for the use of flow cytometry and cell sorting in immunological studies (second edition). Eur J Immunol 49, $1457-1973$.

Dobin, A., Davis, C.A., Schlesinger, F., Drenkow, J., Zaleski, C., Jha, S., Batut, P., Chaisson, M., and Gingeras, T.R. (2013). STAR: ultrafast universal RNA-seq aligner. Bioinformatics $29,15-21$.

Dorsaz, S., Coste, A.T., and Sanglard, D. (2017). Red-Shifted Firefly Luciferase Optimized for Candida albicans In vivo Bioluminescence Imaging. Front Microbiol 8, 1478.

Du, H., Guan, G., Li, X., Gulati, M., Tao, L., Cao, C., Johnson, A.D., Nobile, C.J., and Huang, G. (2015). N-Acetylglucosamine-Induced Cell Death in Candida albicans and Its Implications for Adaptive Mechanisms of Nutrient Sensing in Yeasts. mBio 6, e0137601315 .

Dunker, C., Polke, M., Schulze-Richter, B., Schubert, K., Rudolphi, S., Gressler, A.E., Pawlik, T., Prada Salcedo, J.P., Niemiec, M.J., Slesiona-Kunzel, S., et al. (2021). Rapid proliferation due to better metabolic adaptation results in full virulence of a filament-deficient Candida albicans strain. Nat Commun 12, 3899.

Gaffen, S.L., and Moutsopoulos, N.M. (2020). Regulation of host-microbe interactions at oral mucosal barriers by type 17 immunity. Sci Immunol 5 .

Ghannoum, M.A., Jurevic, R.J., Mukherjee, P.K., Cui, F., Sikaroodi, M., Naqvi, A., and Gillevet, P.M. (2010). Characterization of the oral fungal microbiome (mycobiome) in healthy individuals. PLoS pathogens 6, e1000713.

Gillum, A.M., Tsay, E.Y., and Kirsch, D.R. (1984). Isolation of the Candida albicans gene for orotidine-5'-phosphate decarboxylase by complementation of S. cerevisiae ura3 and E. coli pyrF mutations. Mol Gen Genet 198, 179-182.

Gladiator, A., Wangler, N., Trautwein-Weidner, K., and LeibundGut-Landmann, S. (2013). Cutting edge: IL-17-secreting innate lymphoid cells are essential for host defense against fungal infection. J Immunol 190, 521-525.

Graf, K., Last, A., Gratz, R., Allert, S., Linde, S., Westermann, M., Groger, M., Mosig, A.S., Gresnigt, M.S., and Hube, B. (2019). Keeping Candida commensal: how lactobacilli antagonize pathogenicity of Candida albicans in an in vitro gut model. Disease models \& mechanisms 12 .

Gu, Z., Eils, R., and Schlesner, M. (2016). Complex heatmaps reveal patterns and correlations in multidimensional genomic data. Bioinformatics 32, 2847-2849.

Guiducci, E., Lemberg, C., Kung, N., Schraner, E., Theocharides, A.P.A., and LeibundGutLandmann, S. (2018). Candida albicans-Induced NETosis Is Independent of Peptidylarginine Deiminase 4. Front Immunol 9, 1573. 
Hamdy, R., Soliman, S.S.M., Alsaadi, A.I., Fayed, B., Hamoda, A., Elseginy, S.A., Husseiny, M.I., and Ibrahim, A.S. (2020). Design and Synthesis of New Drugs Inhibitors of Candida albicans Hyphae and Biofilm Formation by Upregulating the Expression of TUP1 Transcription Repressor Gene. European Journal of Pharmaceutical Sciences, 105327.

Hirakawa, M.P., Martinez, D.A., Sakthikumar, S., Anderson, M.Z., Berlin, A., Gujja, S., Zeng, Q., Zisson, E., Wang, J.M., Greenberg, J.M., et al. (2015). Genetic and phenotypic intra-species variation in Candida albicans. Genome Res 25, 413-425.

Huang, M.Y., Woolford, C.A., May, G., McManus, C.J., and Mitchell, A.P. (2019). Circuit diversification in a biofilm regulatory network. PLoS pathogens 15, e1007787.

Kalinin, A.E., Kajava, A.V., and Steinert, P.M. (2002). Epithelial barrier function: assembly and structural features of the cornified cell envelope. Bioessays 24, 789-800.

Kannan, A., Asner, S.A., Trachsel, E., Kelly, S., Parker, J., and Sanglard, D. (2019).

Comparative Genomics for the Elucidation of Multidrug Resistance in Candida lusitaniae. mBio 10 .

Kim, D., Pertea, G., Trapnell, C., Pimentel, H., Kelley, R., and Salzberg, S.L. (2013).

TopHat2: accurate alignment of transcriptomes in the presence of insertions, deletions and gene fusions. Genome Biol 14, R36.

Kirchner, F., and LeibundGut-Landmann, S. (2020). Tissue-resident memory Th17 cells maintain stable fungal commensalism in the oral mucosa. Mucosal Immunol under review.

Kirchner, F.R., Littringer, K., Altmeier, S., Tran, V.D.T., Schonherr, F., Lemberg, C., Pagni, M., Sanglard, D., Joller, N., and LeibundGut-Landmann, S. (2019). Persistence of Candida albicans in the Oral Mucosa Induces a Curbed Inflammatory Host Response That Is Independent of Immunosuppression. Front Immunol 10, 330.

Law, C.W., Chen, Y., Shi, W., and Smyth, G.K. (2014). voom: Precision weights unlock linear model analysis tools for RNA-seq read counts. Genome Biol 15, R29.

Legrand, M., Bachellier-Bassi, S., Lee, K.K., Chaudhari, Y., Tournu, H., Arbogast, L., Boyer, H., Chauvel, M., Cabral, V., Maufrais, C., et al. (2018). Generating genomic platforms to study Candida albicans pathogenesis. Nucleic Acids Res 46, 6935-6949.

Li, J., Vinh, D.C., Casanova, J.L., and Puel, A. (2017). Inborn errors of immunity underlying fungal diseases in otherwise healthy individuals. Curr Opin Microbiol 40, 46-57.

Liu, J., Willems, H.M.E., Sansevere, E.A., Allert, S., Barker, K.S., Lowes, D.J., Dixson, A.C., Xu, Z., Miao, J., DeJarnette, C., et al. (2021). A variant ECE1 allele contributes to reduced pathogenicity of Candida albicans during vulvovaginal candidiasis. PLoS pathogens 17, e1009884.

MacCallum, D.M., Castillo, L., Nather, K., Munro, C.A., Brown, A.J., Gow, N.A., and Odds, F.C. (2009). Property differences among the four major Candida albicans strain clades. Eukaryot Cell 8, 373-387.

Mailander-Sanchez, D., Braunsdorf, C., Grumaz, C., Muller, C., Lorenz, S., Stevens, P., Wagener, J., Hebecker, B., Hube, B., Bracher, F., et al. (2017). Antifungal defense of probiotic Lactobacillus rhamnosus GG is mediated by blocking adhesion and nutrient depletion. PloS one 12, e0184438.

Marakalala, M.J., Vautier, S., Potrykus, J., Walker, L.A., Shepardson, K.M., Hopke, A., Mora-Montes, H.M., Kerrigan, A., Netea, M.G., Murray, G.I., et al. (2013). Differential 
adaptation of Candida albicans in vivo modulates immune recognition by dectin-1. PLoS pathogens 9, e1003315.

Mishra, A.A., and Koh, A.Y. (2021). The microbial and host factors that govern Candida gastrointestinal colonization and dissemination. Curr Opin Microbiol 63, 29-35.

Mogavero, S., Sauer, F.M., Brunke, S., Allert, S., Schulz, D., Wisgott, S., Jablonowski, N., Elshafee, O., Kruger, T., Kniemeyer, O., et al. (2021). Candidalysin delivery to the invasion pocket is critical for host epithelial damage induced by Candida albicans. Cell Microbiol, e13378.

Moran, G.P., MacCallum, D.M., Spiering, M.J., Coleman, D.C., and Sullivan, D.J. (2007). Differential regulation of the transcriptional repressor NRG1 accounts for altered host-cell interactions in Candida albicans and Candida dubliniensis. Mol Microbiol 66, 915-929.

Moye, Z.D., Burne, R.A., and Zeng, L. (2014). Uptake and metabolism of Nacetylglucosamine and glucosamine by Streptococcus mutans. Appl Environ Microbiol 80, 5053-5067.

Moyes, D.L., Wilson, D., Richardson, J.P., Mogavero, S., Tang, S.X., Wernecke, J., Hofs, S., Gratacap, R.L., Robbins, J., Runglall, M., et al. (2016). Candidalysin is a fungal peptide toxin critical for mucosal infection. Nature 532, 64-68.

Murad, A.M., Leng, P., Straffon, M., Wishart, J., Macaskill, S., MacCallum, D., Schnell, N., Talibi, D., Marechal, D., Tekaia, F., et al. (2001). NRG1 represses yeast-hypha morphogenesis and hypha-specific gene expression in Candida albicans. EMBO J 20, 47424752.

Noble, S.M., French, S., Kohn, L.A., Chen, V., and Johnson, A.D. (2010). Systematic screens of a Candida albicans homozygous deletion library decouple morphogenetic switching and pathogenicity. Nat Genet 42, 590-598.

Ost, K.S., O'Meara, T.R., Stephens, W.Z., Chiaro, T., Zhou, H., Penman, J., Bell, R., Catanzaro, J.R., Song, D., Singh, S., et al. (2021). Adaptive immunity induces mutualism between commensal eukaryotes. Nature 596, 114-118.

Pande, K., Chen, C., and Noble, S.M. (2013). Passage through the mammalian gut triggers a phenotypic switch that promotes Candida albicans commensalism. Nat Genet 45, 1088-1091.

Perez, J.C., Kumamoto, C.A., and Johnson, A.D. (2013). Candida albicans commensalism and pathogenicity are intertwined traits directed by a tightly knit transcriptional regulatory circuit. PLoS Biol 11, e1001510.

Peters, B.M., Palmer, G.E., Nash, A.K., Lilly, E.A., Fidel, P.L., Jr., and Noverr, M.C. (2014). Fungal morphogenetic pathways are required for the hallmark inflammatory response during Candida albicans vaginitis. Infect Immun 82, 532-543.

Phan, Q.T., Myers, C.L., Fu, Y., Sheppard, D.C., Yeaman, M.R., Welch, W.H., Ibrahim, A.S., Edwards, J.E., Jr., and Filler, S.G. (2007). Als3 is a Candida albicans invasin that binds to cadherins and induces endocytosis by host cells. PLoS Biol 5, e64.

Rahman, D., Mistry, M., Thavaraj, S., Challacombe, S.J., and Naglik, J.R. (2007). Murine model of concurrent oral and vaginal Candida albicans colonization to study epithelial hostpathogen interactions. Microbes Infect 9, 615-622.

Reuss, O., Vik, A., Kolter, R., and Morschhauser, J. (2004). The SAT1 flipper, an optimized tool for gene disruption in Candida albicans. Gene 341, 119-127. 
Richardson, J.P., Mogavero, S., Moyes, D.L., Blagojevic, M., Kruger, T., Verma, A.H., Coleman, B.M., De La Cruz Diaz, J., Schulz, D., Ponde, N.O., et al. (2018). Processing of Candida albicans Ece1p Is Critical for Candidalysin Maturation and Fungal Virulence. mBio 9.

Robinson, M.D., and Oshlack, A. (2010). A scaling normalization method for differential expression analysis of RNA-seq data. Genome Biol 11, R25.

Ropars, J., Maufrais, C., Diogo, D., Marcet-Houben, M., Perin, A., Sertour, N., Mosca, K., Permal, E., Laval, G., Bouchier, C., et al. (2018). Gene flow contributes to diversification of the major fungal pathogen Candida albicans. Nat Commun 9, 2253.

Rupniak, H.T., Rowlatt, C., Lane, E.B., Steele, J.G., Trejdosiewicz, L.K., Laskiewicz, B., Povey, S., and Hill, B.T. (1985). Characteristics of four new human cell lines derived from squamous cell carcinomas of the head and neck. J Natl Cancer Inst 75, 621-635.

Saville, S.P., Lazzell, A.L., Monteagudo, C., and Lopez-Ribot, J.L. (2003). Engineered control of cell morphology in vivo reveals distinct roles for yeast and filamentous forms of Candida albicans during infection. Eukaryot Cell 2, 1053-1060.

Schaller, M., Schackert, C., Korting, H.C., Januschke, E., and Hube, B. (2000). Invasion of Candida albicans correlates with expression of secreted aspartic proteinases during experimental infection of human epidermis. J Invest Dermatol 114, 712-717.

Schmieder, R., and Edwards, R. (2011). Quality control and preprocessing of metagenomic datasets. Bioinformatics 27, 863-864.

Schönherr, F.A., Sparber, F., Kirchner, F.R., Guiducci, E., Trautwein-Weidner, K., Gladiator, A., Sertour, N., Hetzel, U., Le, G.T.T., Pavelka, N., et al. (2017). The intraspecies diversity of $\mathrm{C}$. albicans triggers qualitatively and temporally distinct host responses that determine the balance between commensalism and pathogenicity. Mucosal Immunol 10, 1335-1350.

Scully, C., el-Kabir, M., and Samaranayake, L.P. (1994). Candida and oral candidosis: a review. Crit Rev Oral Biol Med 5, 125-157.

Shen, J., Guo, W., and Kohler, J.R. (2005). CaNAT1, a heterologous dominant selectable marker for transformation of Candida albicans and other pathogenic Candida species. Infect Immun 73, 1239-1242.

Sheppard, D.C., Yeaman, M.R., Welch, W.H., Phan, Q.T., Fu, Y., Ibrahim, A.S., Filler, S.G., Zhang, M., Waring, A.J., and Edwards, J.E., Jr. (2004). Functional and structural diversity in the Als protein family of Candida albicans. J Biol Chem 279, 30480-30489.

Solis, N.V., and Filler, S.G. (2012). Mouse model of oropharyngeal candidiasis. Nat Protoc 7, 637-642.

Tso, G.H.W., Reales-Calderon, J.A., Tan, A.S.M., Sem, X., Le, G.T.T., Tan, T.G., Lai, G.C., Srinivasan, K.G., Yurieva, M., Liao, W., et al. (2018). Experimental evolution of a fungal pathogen into a gut symbiont. Science 362, 589-595.

Vautier, S., Drummond, R.A., Chen, K., Murray, G.I., Kadosh, D., Brown, A.J., Gow, N.A., MacCallum, D.M., Kolls, J.K., and Brown, G.D. (2015). Candida albicans colonization and dissemination from the murine gastrointestinal tract: the influence of morphology and Th17 immunity. Cell Microbiol 17, 445-450.

Wachtler, B., Citiulo, F., Jablonowski, N., Forster, S., Dalle, F., Schaller, M., Wilson, D., and Hube, B. (2012). Candida albicans-epithelial interactions: dissecting the roles of active 
penetration, induced endocytosis and host factors on the infection process. PLoS One 7 , e36952.

Wachtler, B., Wilson, D., Haedicke, K., Dalle, F., and Hube, B. (2011). From attachment to damage: defined genes of Candida albicans mediate adhesion, invasion and damage during interaction with oral epithelial cells. PLoS One 6, e17046.

Williams, R.B., and Lorenz, M.C. (2020). Multiple Alternative Carbon Pathways Combine To Promote Candida albicans Stress Resistance, Immune Interactions, and Virulence. mBio 11 .

Witchley, J.N., Penumetcha, P., Abon, N.V., Woolford, C.A., Mitchell, A.P., and Noble, S.M. (2019). Candida albicans Morphogenesis Programs Control the Balance between Gut Commensalism and Invasive Infection. Cell Host Microbe 25, 432-443 e436.

Yu, G., Li, F., Qin, Y., Bo, X., Wu, Y., and Wang, S. (2010). GOSemSim: an R package for measuring semantic similarity among GO terms and gene products. Bioinformatics 26, 976978.

Znaidi, S., van Wijlick, L., Hernandez-Cervantes, A., Sertour, N., Desseyn, J.L., Vincent, F., Atanassova, R., Gouyer, V., Munro, C.A., Bachellier-Bassi, S., et al. (2018). Systematic gene overexpression in Candida albicans identifies a regulator of early adaptation to the mammalian gut. Cell Microbiol 20, e12890. 
FIG 1.

A.

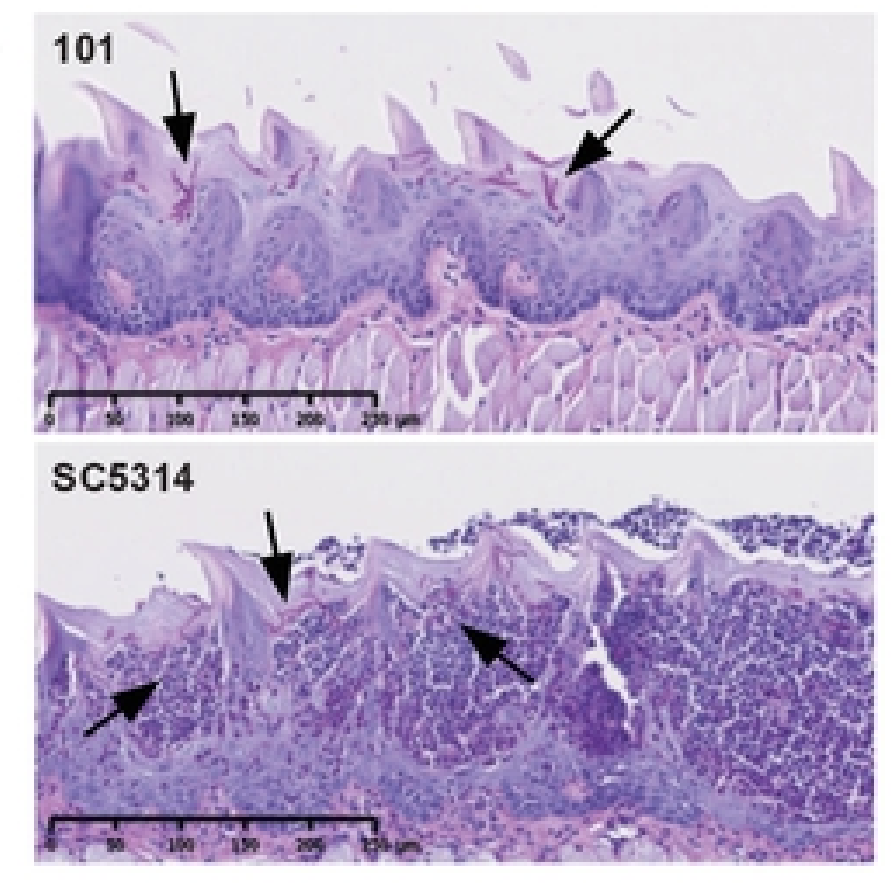

B.

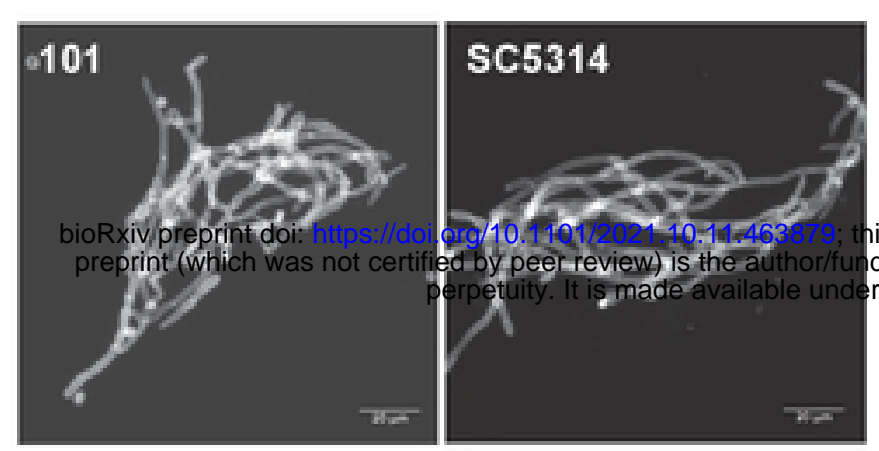

C. 101

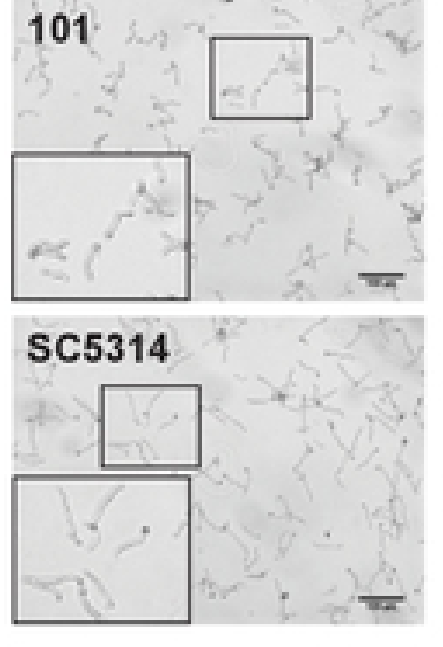

F. 101

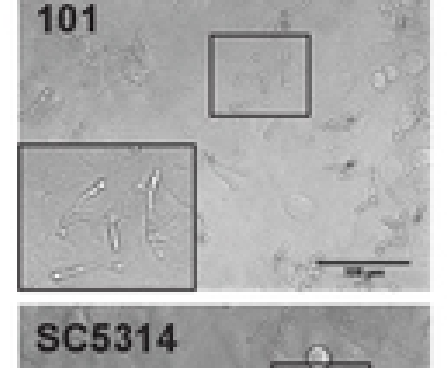

D.

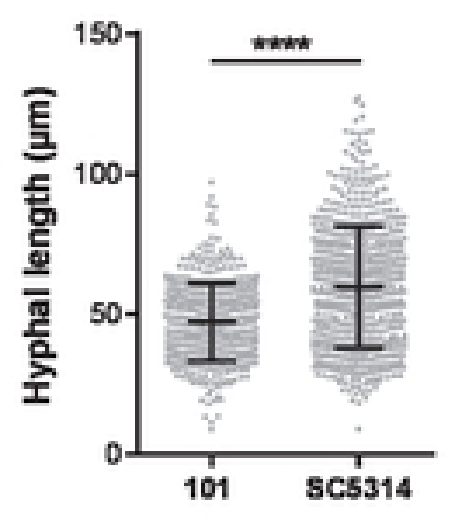

G.

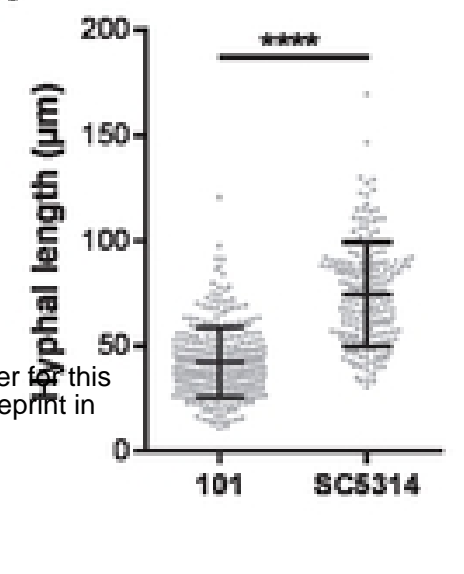

E.

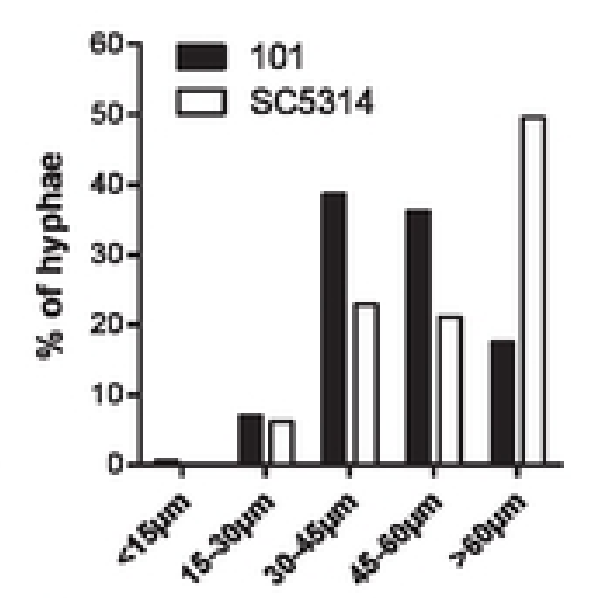

H.

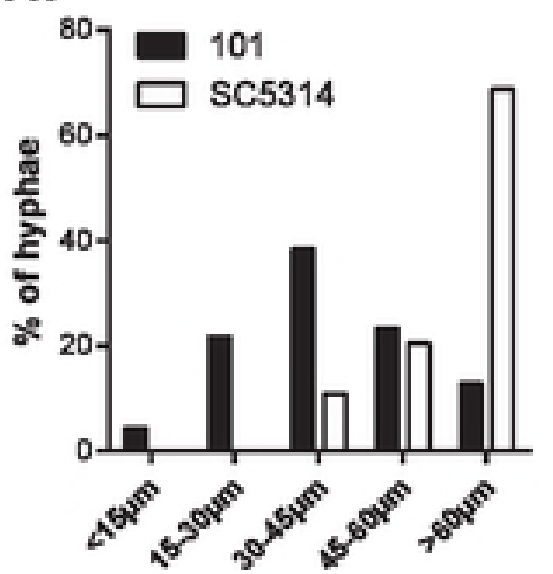

ص SC5314

I.

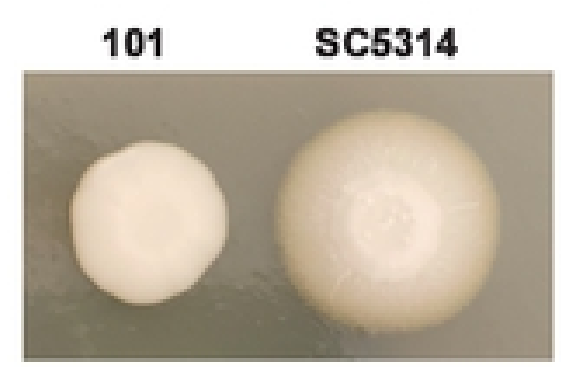


A.

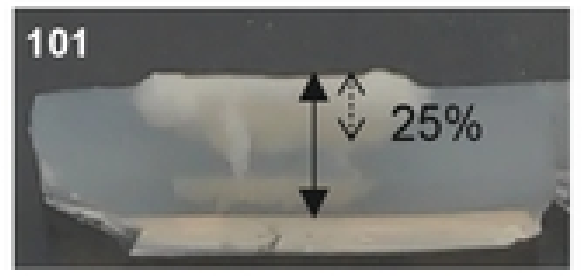

SC5314

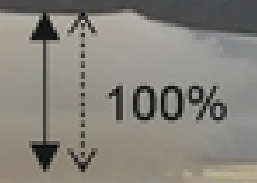

B.

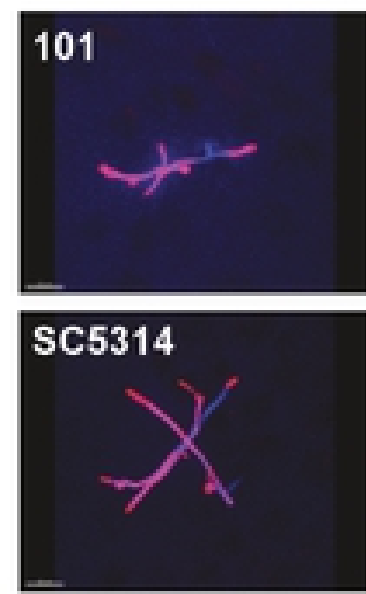

E.

D.

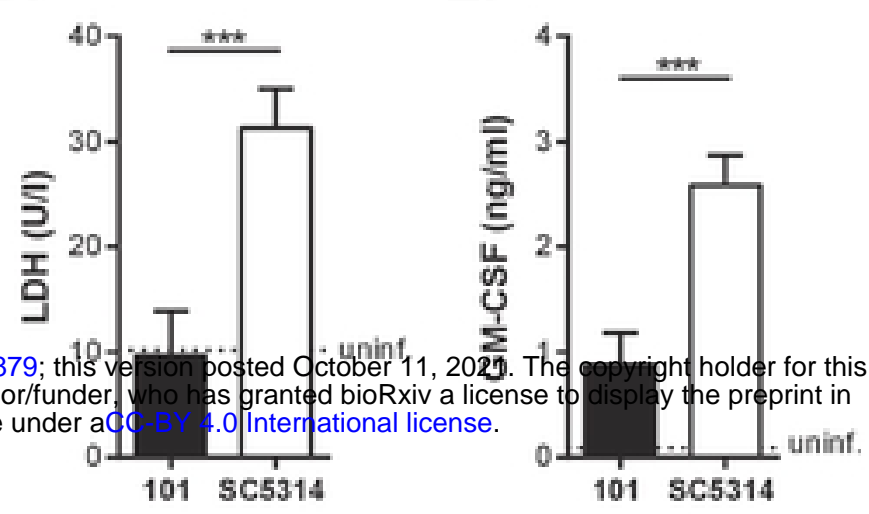

101 SC5314
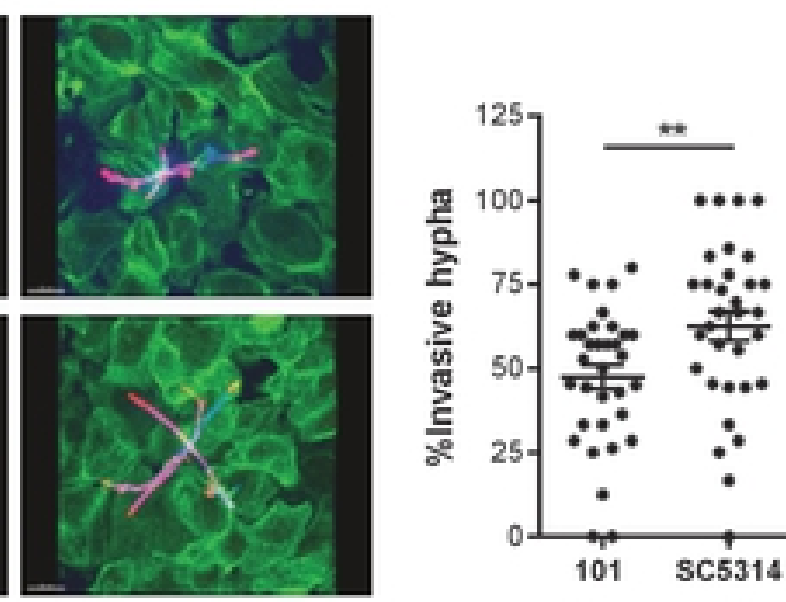

C.

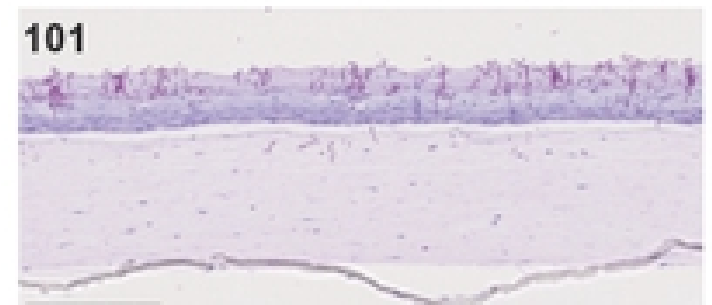

\section{$S C 5314$}

biokxiv preprint doi: https://doi.org/10.1101/2021.10.11.463879; this ve preprint (which was not certified by peer review) is the author/funder

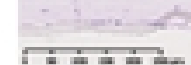

G.

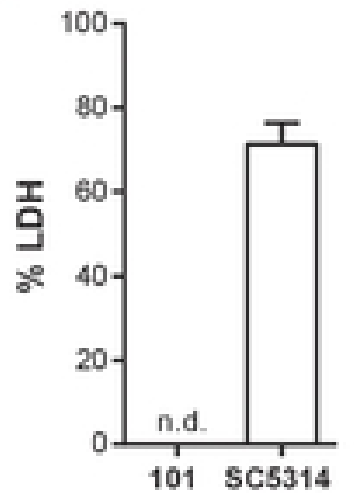

H.

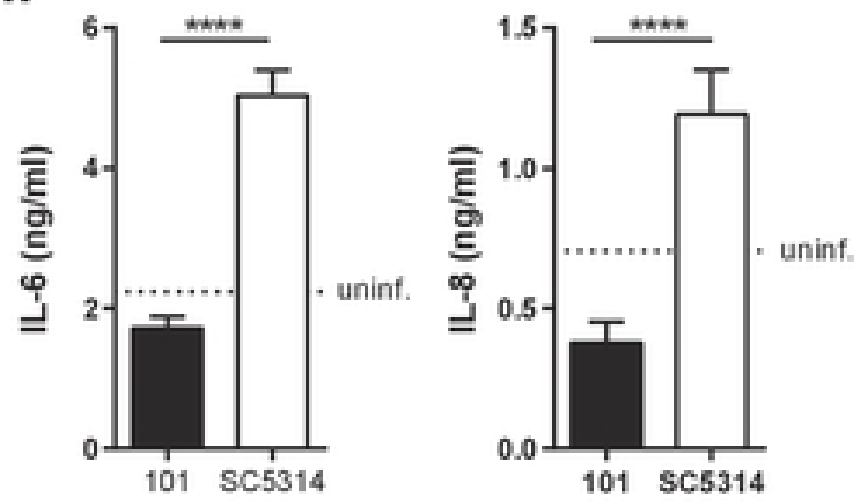

F.
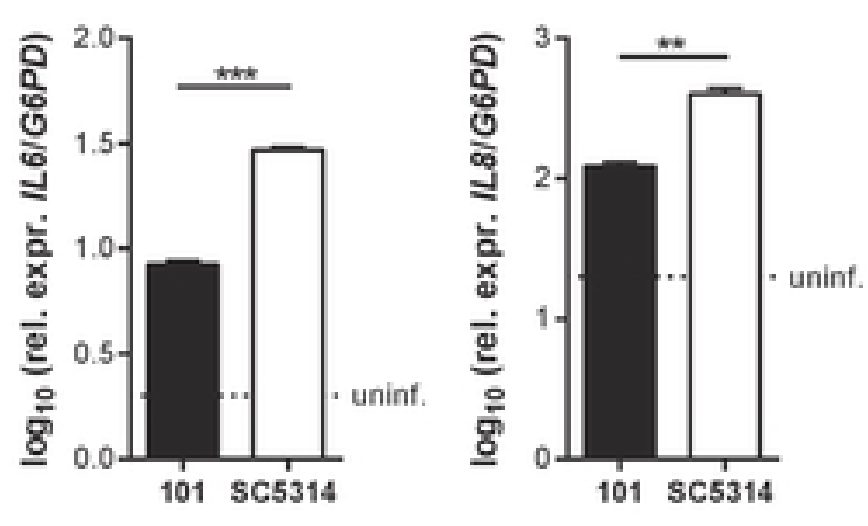
A.

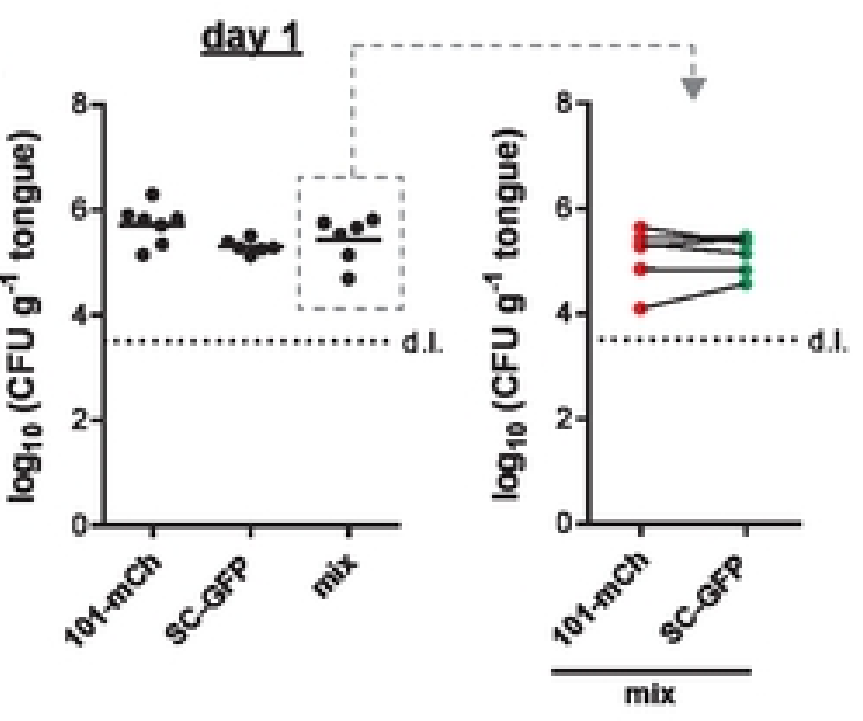

B.

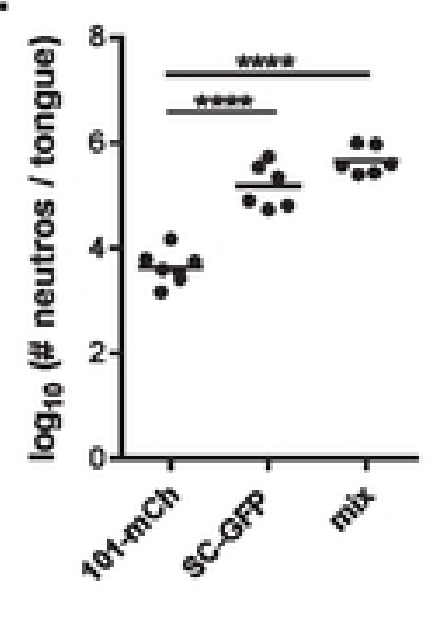

c.

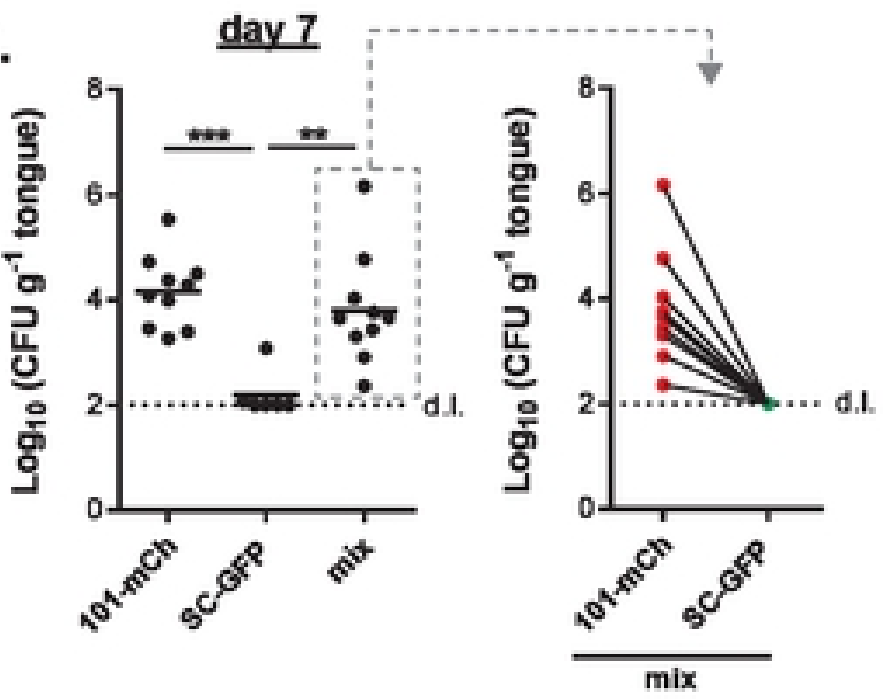

FIG 3

bioRxiv preprint doi: https://doi.org/10.1101/2021.10.11.463879; this version posted October 11, 2021. The copyright holder for this preprint (which was not certified by peer review) is the author/funder, who has granted bioRxiv a license to display the preprint in
perpetuity. It is made available under aCC-BY 4.0 International license. 
A.

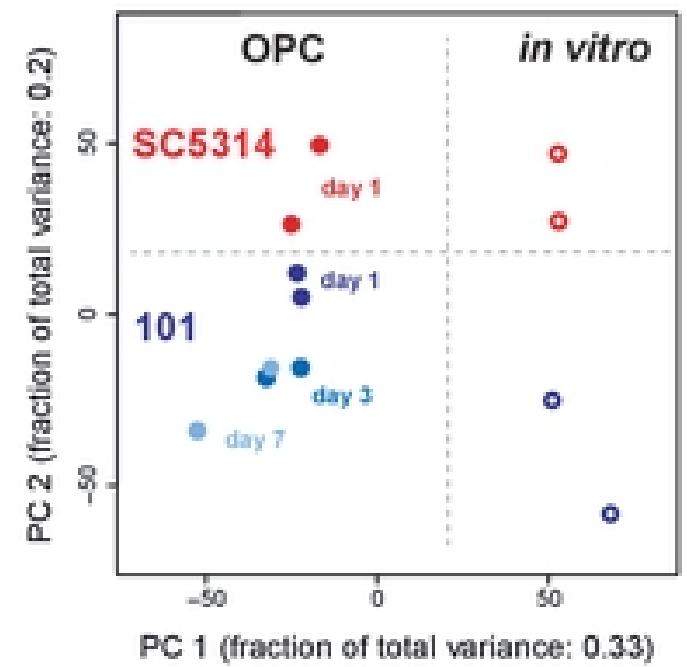

B.

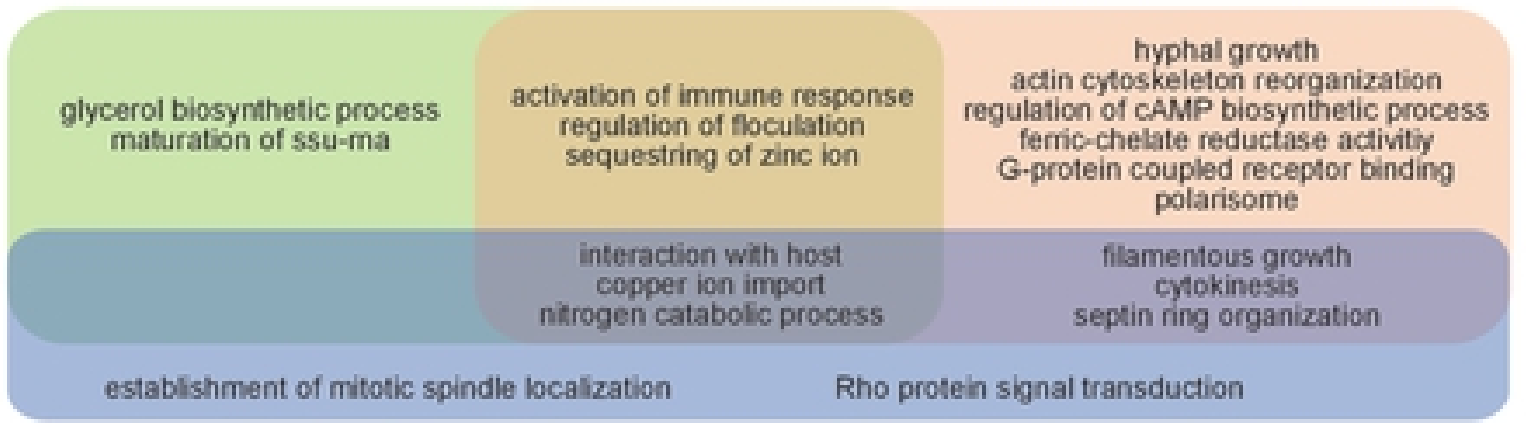

C.

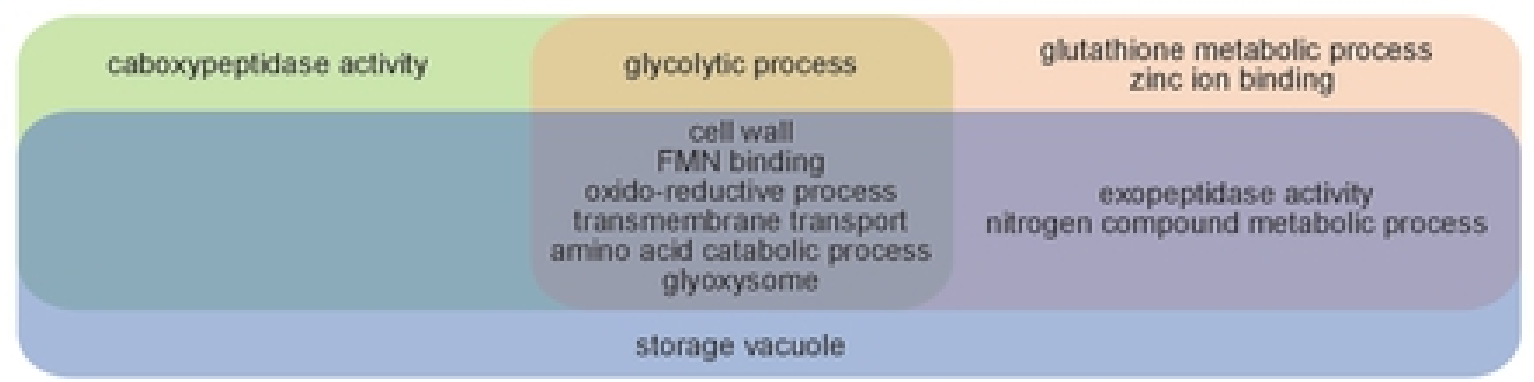

D.

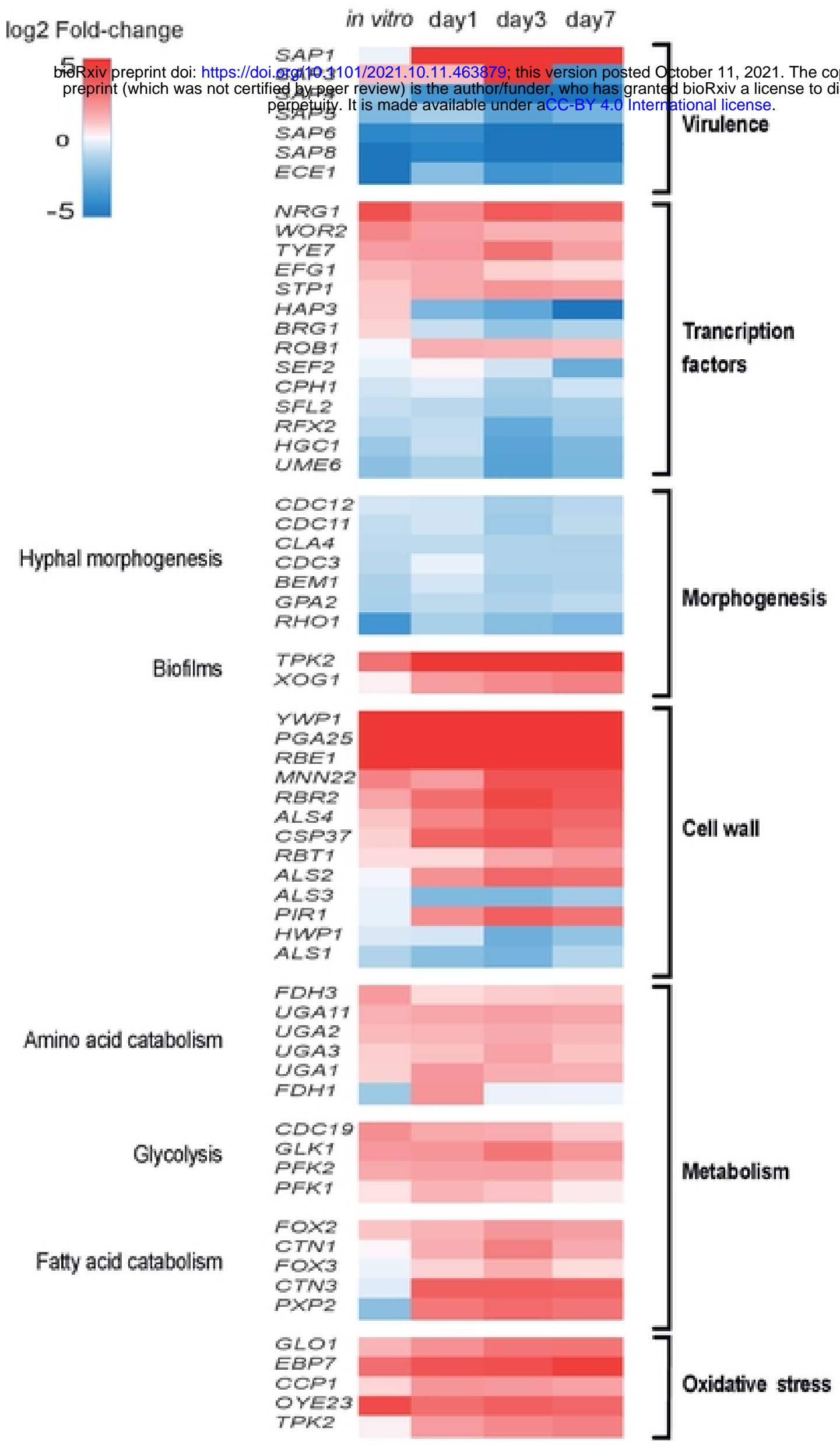


A.

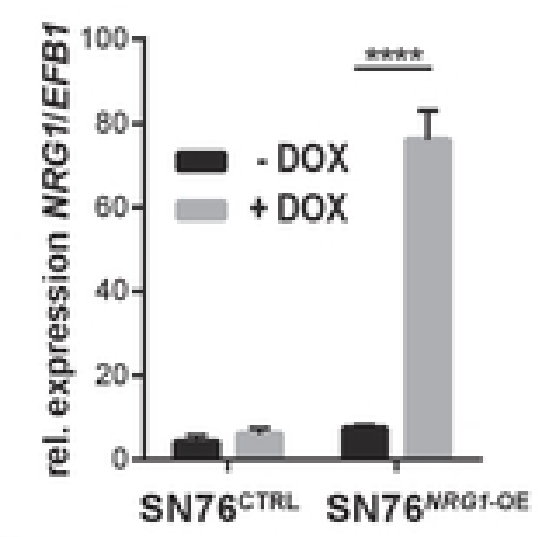

D.

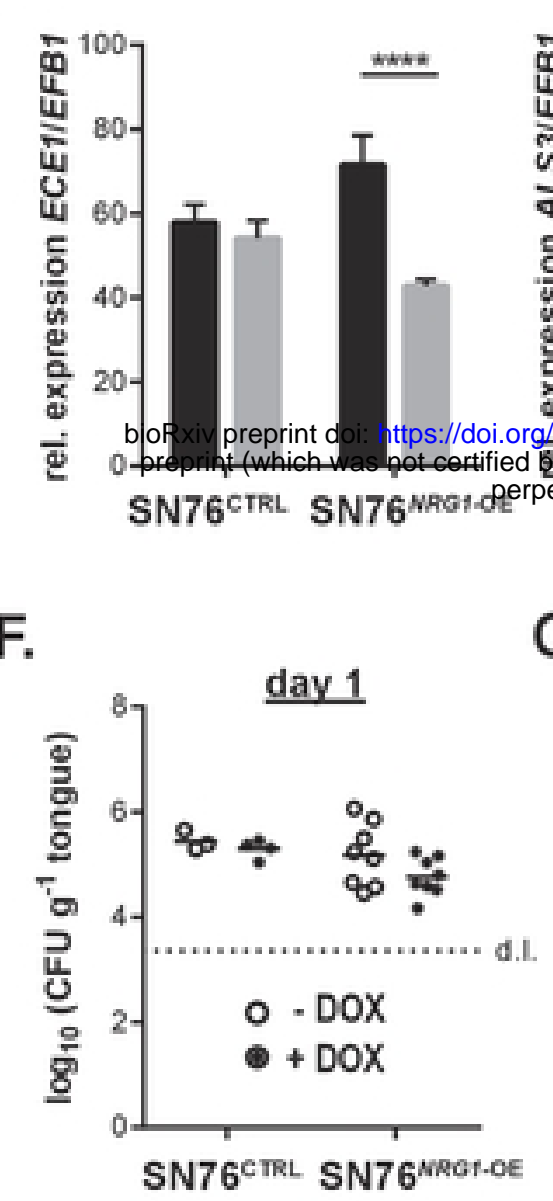

I.

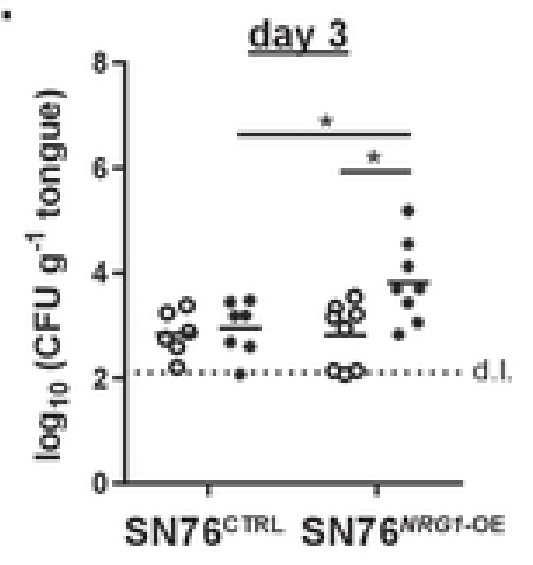

F.
B.

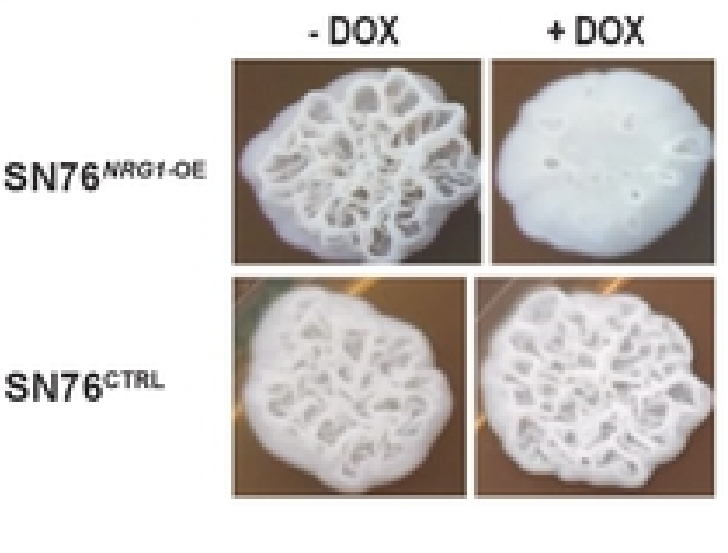

C.

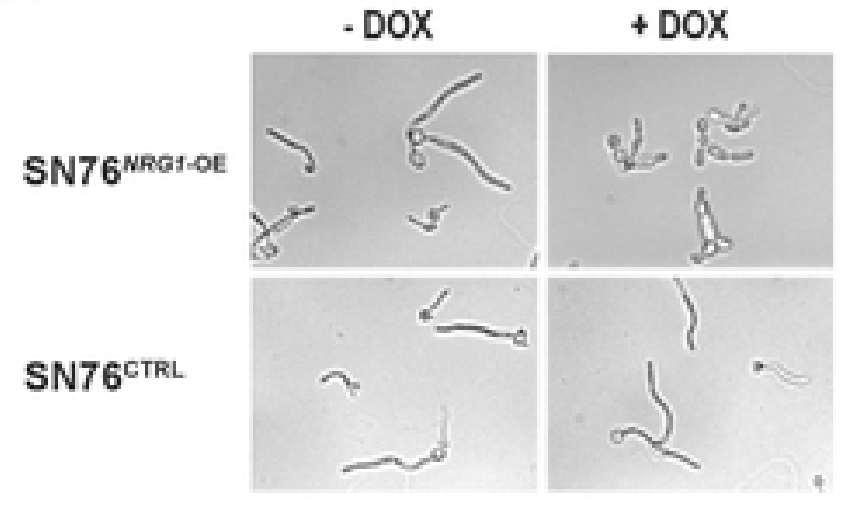

E.

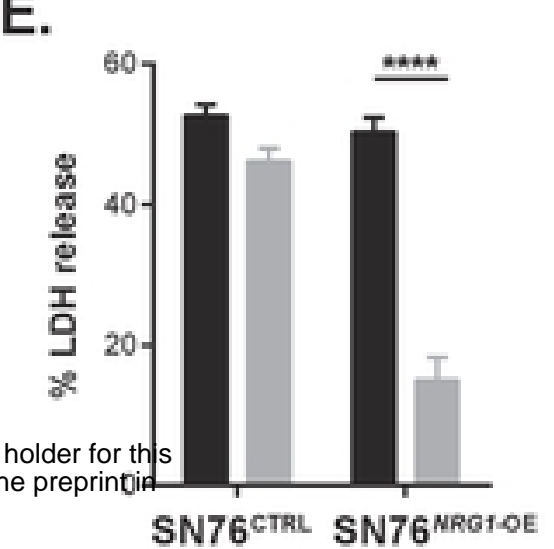

G.
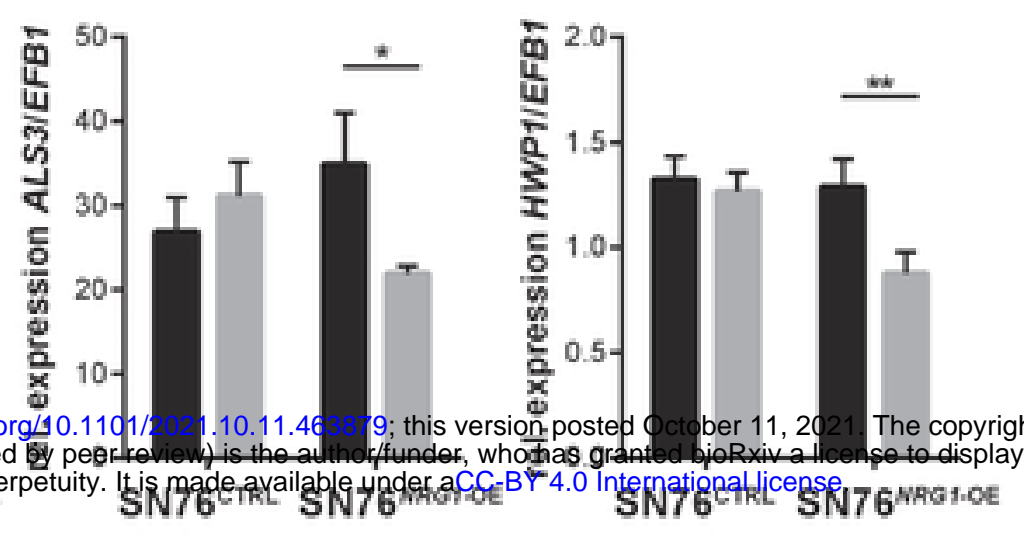

DOX

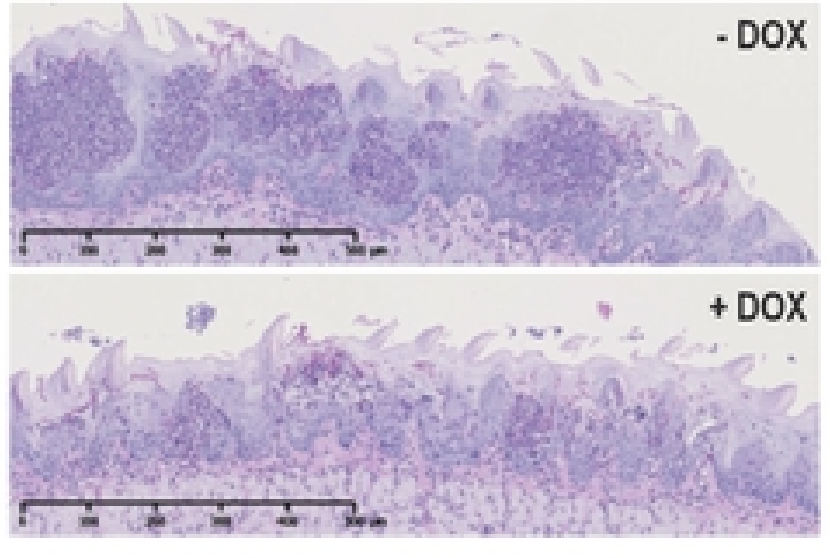

J.

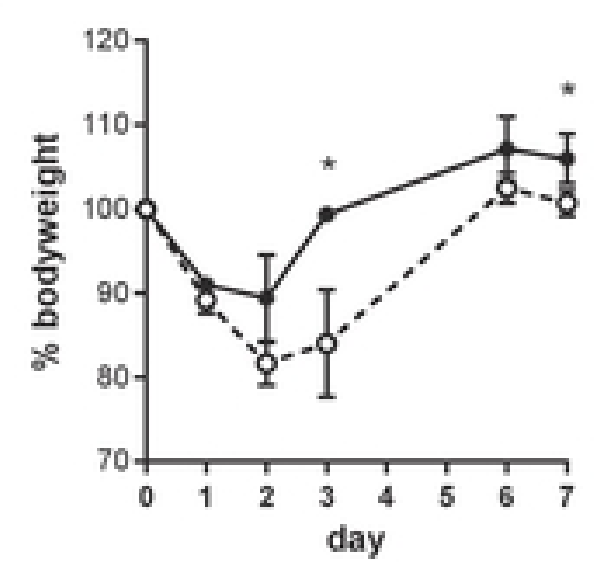

H.

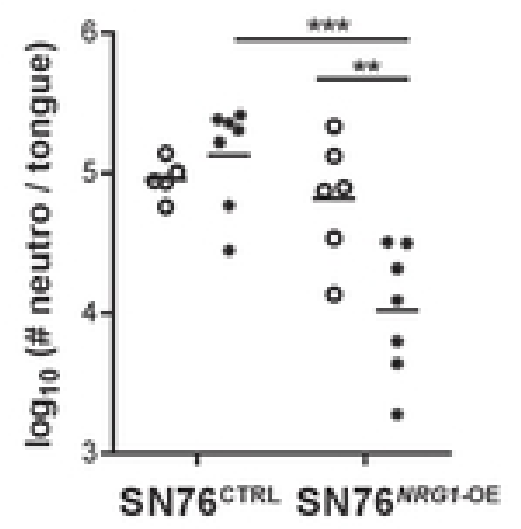


A. ${ }^{200} \rightarrow$ B.
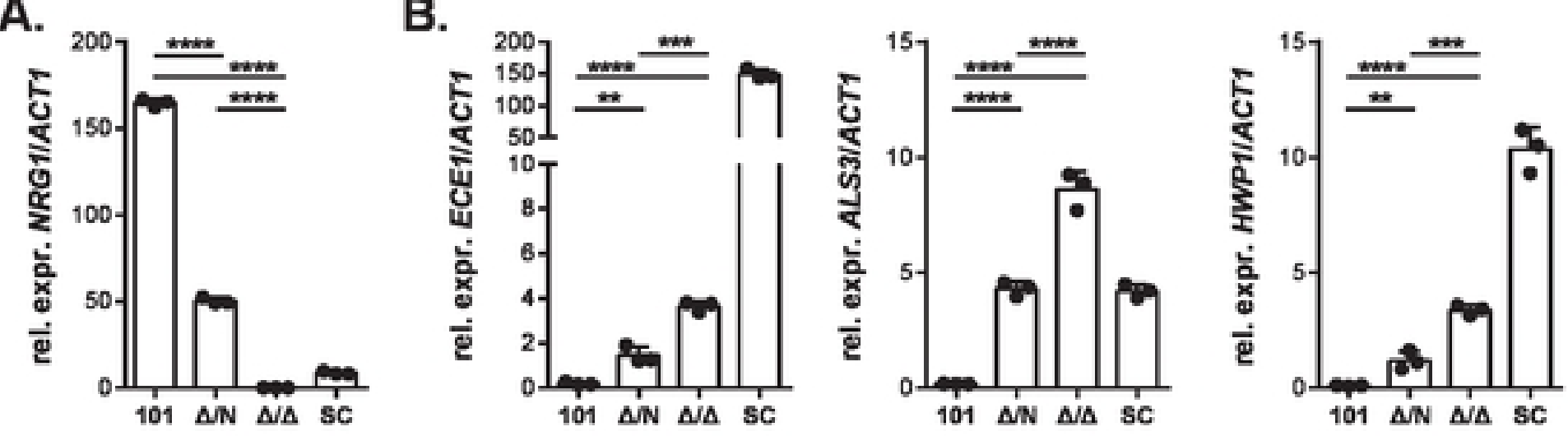

c.
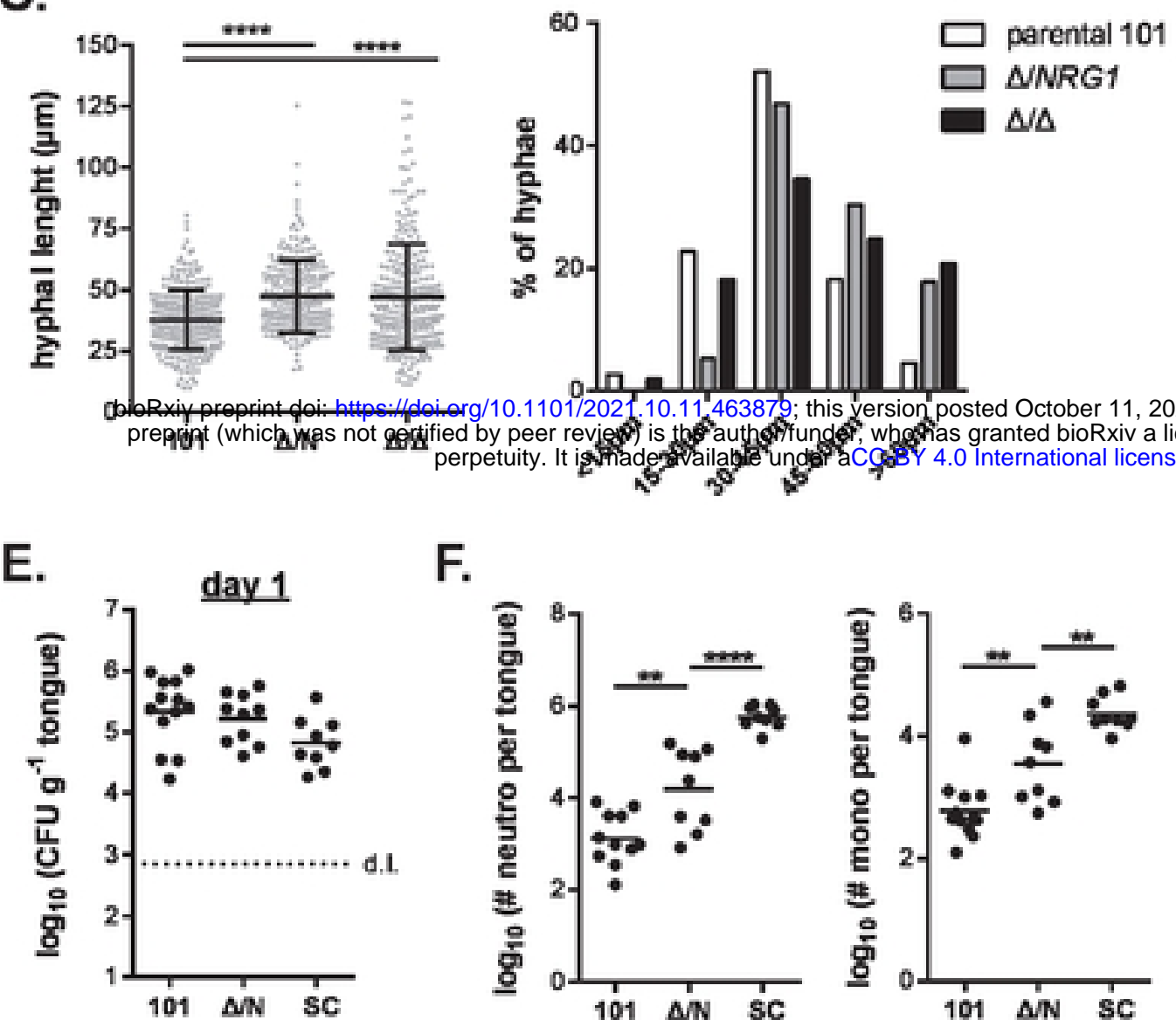

D.

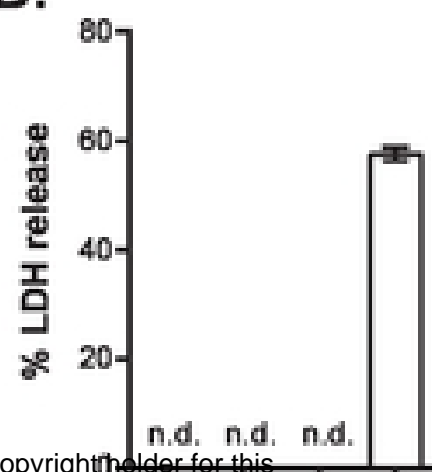

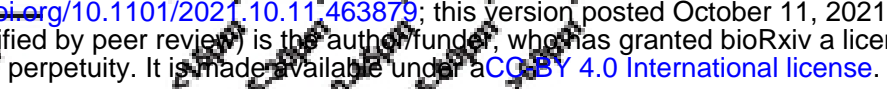

H.

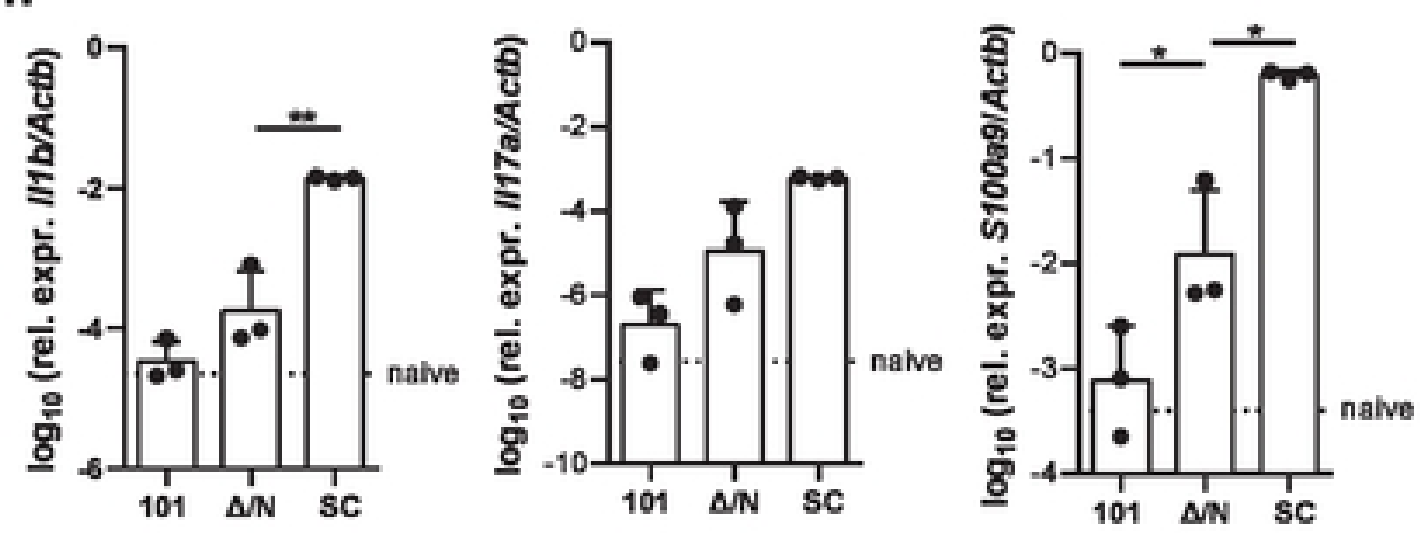

G.
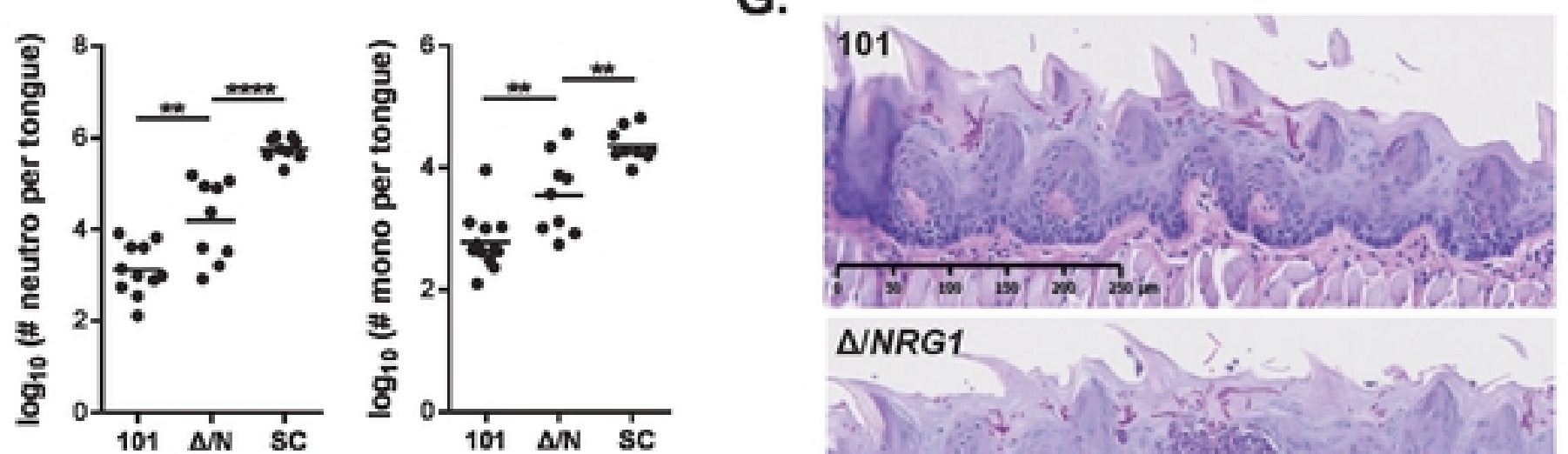

I.
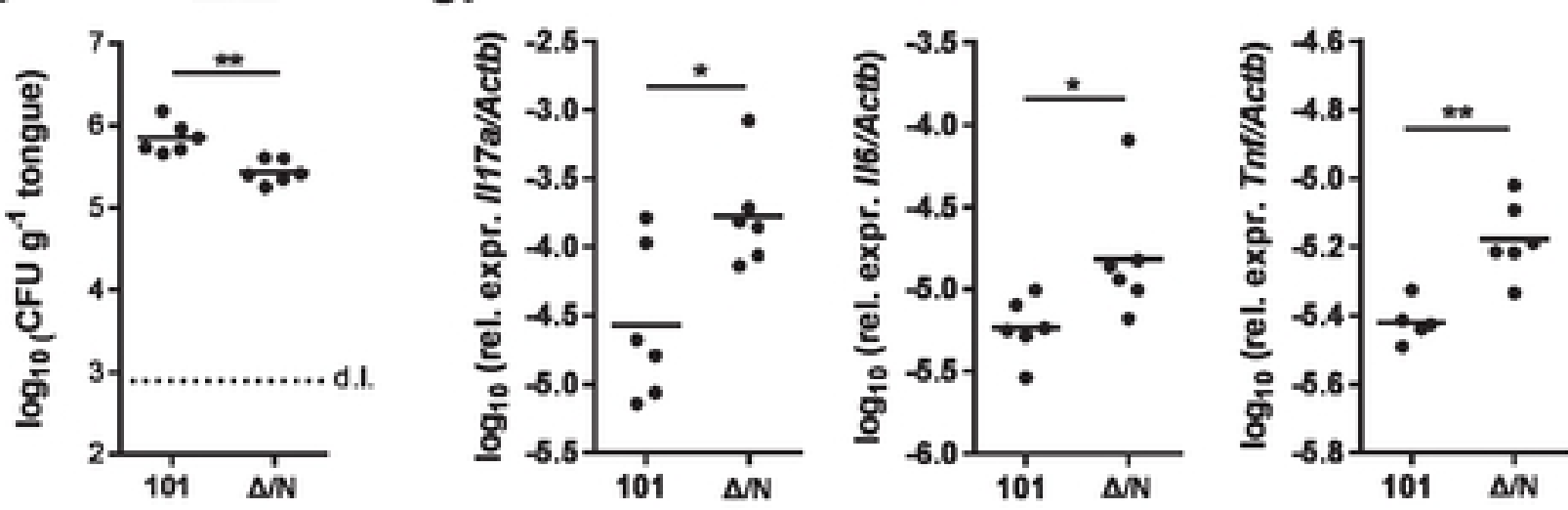
A.

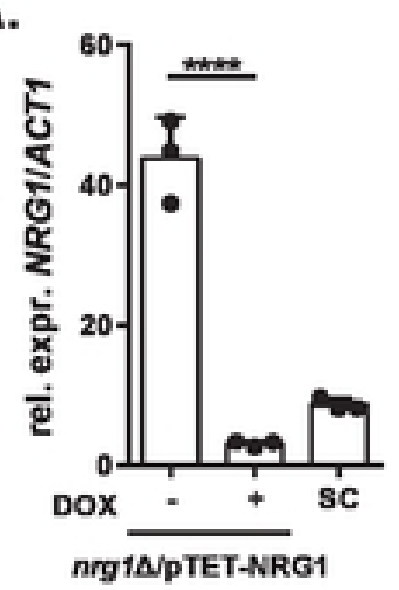

D.

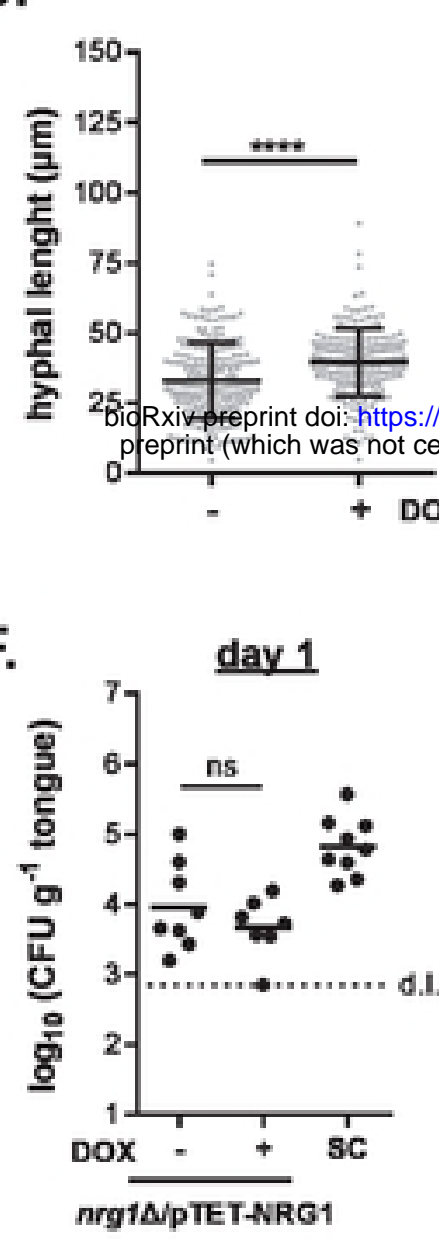

B.
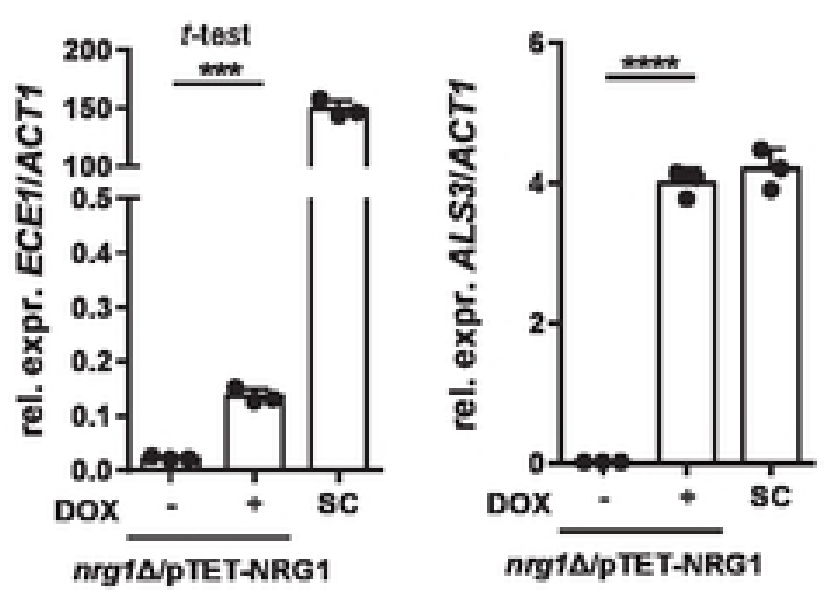

C.

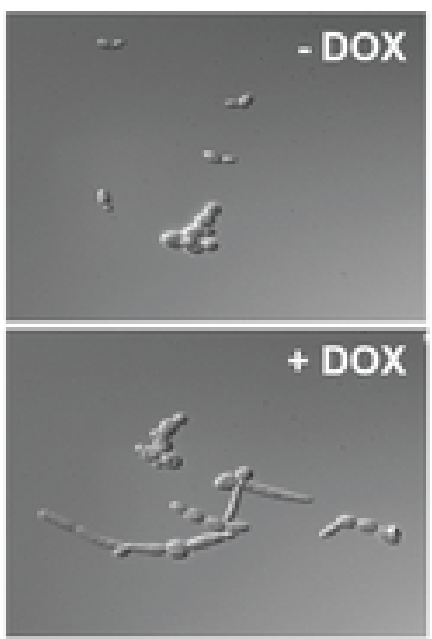

E.

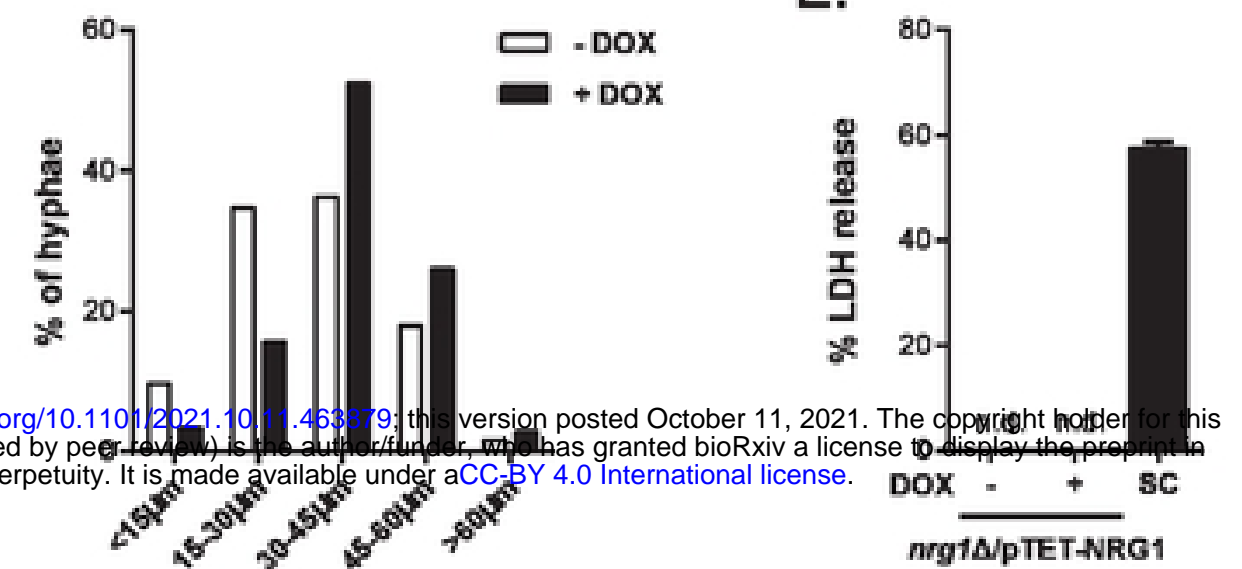

G.
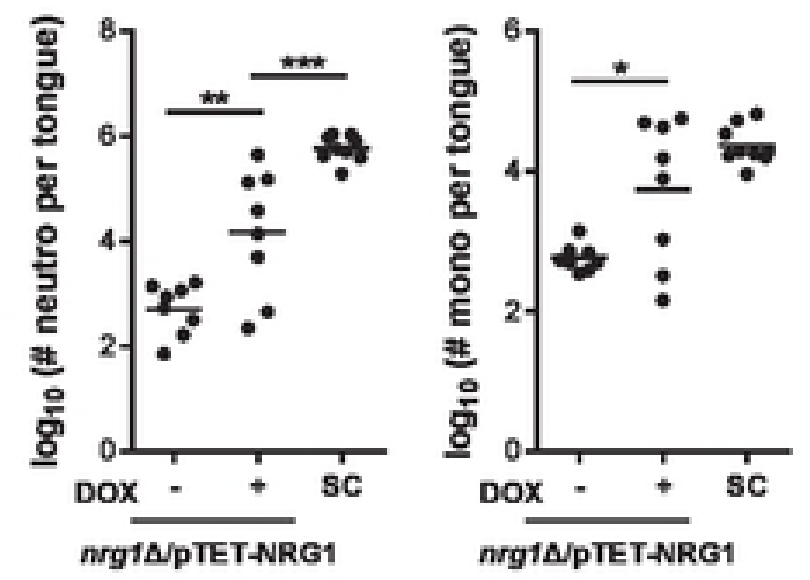